\title{
Multicolor flow cytometric analysis of cryopreserved bovine sperm: A tool for the evaluation of bull fertility
}

\author{
K. Bucher, ${ }^{1}$ E. Malama, ${ }^{1,2 *}$ M. Siuda, ${ }^{1}$ F. Janett, ${ }^{1}$ and H. Bollwein ${ }^{1}$ \\ ${ }^{1}$ Clinic of Reproductive Medicine, Vetsuisse Faculty, University of Zurich, Zurich CH-8057, Switzerland \\ ${ }^{2}$ Veterinary Research Institute, Hellenic Agricultural Organization Demeter, Thermi 57001, Thessaloniki, Greece
}

\section{ABSTRACT}

The study aimed at the analysis of the functional status of cryopreserved bovine sperm using multicolor flow cytometry. The value of sperm functional traits as predictors of bull fertility was further evaluated through a retrospective fertility study. For this purpose, 20 Holstein-Friesian bulls serving as mature sperm donors in an artificial insemination (AI) center were selected based on their annual 56-d non-return rate (\%) after at least 1,000 AI, and were accordingly classified as high (HF; $\mathrm{n}_{\mathrm{HF}}=10$ bulls) or low fertility bulls (LF; $\mathrm{n}_{\mathrm{LF}}=10$ bulls). Four to 5 cryopreserved ejaculates per bull (91 ejaculates in total) were examined immediately after thawing $(0 \mathrm{~h})$ and after a 3 -h incubation at $38^{\circ} \mathrm{C}$ $(3 \mathrm{~h})$. A panel of 5 fluorochromes including calcein violet, propidium iodide, pycoerythrin-conjugated lectin of Arachis hypogea, Fluo-4, and cyanine dye $\operatorname{DiIC}_{1}(5)$ was configured by means of a 3-laser flow cytometer, to simultaneously assess sperm esterase activity, plasma membrane integrity, acrosomal status, intracellular $\mathrm{Ca}^{2+}$ levels, and mitochondrial membrane potential, respectively. The $\%$ relative size of 18 sperm sub-populations showing 2 or more of a combination of the following features was determined: high esterase activity $\left(\mathrm{C}_{\mathrm{pos}}\right)$, intact plasma membrane $\left(\mathrm{PI}_{\text {neg }}\right)$, unstained acrosome $\left(\mathrm{PNA}_{\text {neg }}\right)$, low intracellular $\mathrm{Ca}^{2+}$ levels $\left(\mathrm{F}_{\text {neg }}\right)$, and high mitochondrial membrane potential $\left(\mathrm{M}_{\text {pos }}\right)$. In both fertility groups, $\mathrm{M}_{\mathrm{pos}}$ cells comprised more than 90 and $84 \%$ of $\mathrm{PI}_{\text {neg }} \mathrm{PNA}_{\text {neg }}$ sperm at 0 and $3 \mathrm{~h}$, respectively. The percentage of $\mathrm{C}_{\text {pos }} \mathrm{PI}_{\text {neg }} \mathrm{PNA}_{\text {neg }} \mathrm{F}_{\text {neg }} \mathrm{M}_{\text {pos }}$ sperm did not differ between HF and LF ejaculates; however, the percentage of $\mathrm{F}_{\text {neg }}$ cells within the $\mathrm{PI}_{\text {neg }} \mathrm{PNA}_{\text {neg }}$ and $\mathrm{PI}_{\text {neg }} \mathrm{M}_{\text {pos }}$ sperm populations at $0 \mathrm{~h}$ was higher in the $\mathrm{HF}$ than in the LF bulls. Applying the random forest ensemble learning method, approximately two-thirds of ejaculates could be correctly assigned to their fertility group. The fraction of $\mathrm{F}_{\text {neg }}$ sperm within the $\mathrm{PI}_{\text {neg }} \mathrm{M}_{\text {pos }}$

Received March 5, 2019.

Accepted July 11, 2019.

*Corresponding author: emalama@vetclinics.uzh.ch population at $0 \mathrm{~h}$ was the most important fertility predictor among the 18 defined sperm populations. In conclusion, multicolor flow cytometry offered an insight into the functional heterogeneity of cryopreserved bovine sperm. Indeed, the ability of viable sperm to retain low $\mathrm{Ca}^{2+}$ levels differed between bulls of diverse fertility. A classifier based on selected sperm populations assessed through multicolor flow cytometry could contribute to the prognosis of bull fertility after AI. Key words: bull, sperm, fertility, multicolor, flow cytometry

\section{INTRODUCTION}

The introduction of flow cytometry for sperm quality assessment has been an important landmark in veterinary andrology. A wide variety of fluorochromes with well-defined excitation and emission spectra, commonly referred to as "colors," has been described for the assessment of sperm functional status; plasma membrane and acrosome integrity, mitochondrial status, chromatin integrity, oxidative stress, and intracellular $\mathrm{Ca}^{2+}$ levels are examples of sperm attributes measureable with flow cytometry (Petrunkina and Harrison, 2013). The assessment of single sperm attributes through 1- or 2 -color assays is the common rule even in recent studies investigating elaborate schemes for the prediction of bull fertility (Gliozzi et al., 2017; Kumaresan et al., 2017; Morrell et al., 2017). Independent studies showed a link between bull fertility and several sperm traits that were separately assessed with flow cytometry [e.g., plasma membrane and acrosome integrity (Birck et al., 2010; Christensen et al., 2011), mitochondrial function (Sellem et al., 2015), and $\mathrm{Ca}^{2+}$ levels (Collin et al., 2000)]. Our own preliminary experiments also highlighted the predictive value of the above mentioned single sperm features for bull fertility (Malama et al., 2016; Bucher et al., 2017).

Flow cytometric assays employing 3 or more colors (henceforth referred to as "multicolor") have several advantages against their single-color analogs that could be relevant to sperm examination (Petrunkina and Har- 
rison, 2011). They enable the identification of sperm sub-populations that simultaneously demonstrate a set of different attributes offering a more detailed insight into sperm functional heterogeneity (Amann and Hammerstedt, 1993). Despite the remarkable advancements in other biomedical fields, studies employing multicolor flow cytometry for the examination of bovine sperm remain scarce. In the 2000s, Nagy et al. (2003, 2004) suggested a triple staining with propidium iodide (PI), SYBR-14, and the phycoerythrin-conjugated agglutinin of Arachis hypogaea (PE-PNA) for the evaluation of bovine sperm plasma membrane and acrosome integrity. Within a short amount of time, another triple combination of fluorophores, Merocyanine 540/Yo-Pro $1 /$ Hoechst 33342, was reported for the monitoring of plasma membrane destabilization during cryopreservation and motile sperm selection in the bovine (Hallap et al., 2006). Kanno et al. (2016) extended the 3-color assay already published by Nagy et al. (2003) establishing the quadruple staining PI/SYBR-14/PE-PNA/Mito Tracker Deep Red FM for the combined assessment of sperm viability, acrosomal status, and mitochondrial membrane potential (MMP); however, the results of their experiment were not linked to field fertility.

The assortment of fluorescent markers used in biomedical research constantly expands, further enhancing the application of multicolor assays. The violet-excitable direct probe Calcein Violet AM, an indicator of intracellular esterase activity, and the red-excitable cyanine dye $1,1^{\prime}, 3,3,3^{\prime}, 3^{\prime}$-hexamethylindodicarbocyanine iodide $\left[\operatorname{DiIC}_{1}(5)\right]$, a MMP marker, are suitable examples of fluorochromes that could be used in multicolor experiments incorporating more than one laser (Petrunkina and Harrison, 2013). The combination of such fluorochromes with already well-established dyes that absorb light at the blue region, such as PI, PE-PNA, and the $\mathrm{Ca}^{2+}$ sensor Fluo-4 AM, sounds promising and could provide insight into the role of sperm clusters combining different functional features in bull fertility.
In this direction, the present study aimed (A) to establish a multicolor flow cytometric assay for the quality assessment of commercially produced cryopreserved bovine sperm, and (B) to investigate the predictability of bull fertility through the characterization of sperm functional status with multicolor flow cytometry. For the purposes of the study, a panel consisting of 5 colors was designed and configured with a 3-laser optical system (violet, blue, and red laser); targeted cell features included sperm viability (expressed by plasma membrane integrity and intracellular esterase activity), acrosomal status, MMP, and intracellular $\mathrm{Ca}^{2+}$ levels.

\section{MATERIALS AND METHODS}

\section{Biological Material}

Animal and Sample Selection. The semen samples analyzed in the present study were obtained from mature bulls already serving as proven sperm donors in a commercial AI center. Twenty sires were selected from a pool of Holstein-Friesian bulls with more than 1,000 first services per year (Amann and DeJarnette, 2012). Two of the selected bulls had a number of AI slightly lower than 1,000 [i.e., 917 and 919 AI (Table 1)]. Field fertility data of each bull were systematically recorded in the form of a 56-d non-return rate (NRR, \%) on an annual basis. After computing the mean NRR of the center's bull population $\left(\mathbf{N R R} \mathbf{R}_{\text {mean }}\right)$, bulls with extreme NRR values were assigned to 1 of 2 fertility classes: sires with an individual NRR higher than $\mathrm{NRR}_{\text {mean }}+$ standard deviation were classified as high-fertility bulls (HF), whereas sires with NRR lower than $\mathrm{NRR}_{\text {mean }}$ - standard deviation were characterized as low-fertility bulls (LF). Four to 5 ejaculates per bull (91 ejaculates in total) were selected from a pool of semen batches produced between 2010 and 2015, and used as input for laboratory semen analysis; semen doses from the same bull were produced within a single

Table 1. Classification of selected bulls in the high- (HF) or low-fertility (LF) group according to their annual 56 -d non-return rate $(\mathrm{NRR}, \%)^{1}$

\begin{tabular}{lcccc}
\hline Group & $\begin{array}{c}\text { No. of bulls/ } \\
\text { ejaculates }\end{array}$ & $\begin{array}{c}\text { Mean NRR } \\
(\%)\end{array}$ & $\begin{array}{c}\text { Mean no. } \\
\text { of first services }\end{array}$ & $\begin{array}{c}\text { Annual mean NRR } \\
\text { of population (\%) }\end{array}$ \\
\hline HF & $10 / 46$ & 69.66 & $1,420.90$ & 64.19 to 68.48 \\
LF & $10 / 45$ & $(68.70$ to 72.60$)$ & $(917$ to 2,362$)$ & \\
& & $(56.90$ & $2,041.80$ & $(919$ to 3,518$)$ \\
\hline
\end{tabular}

${ }^{1}$ For each fertility group, the number of examined bulls (and respective ejaculates), mean NRR (\%), and mean number of first services performed per year are demonstrated; when applicable, minimum and maximum values are presented in parentheses. The minimum and maximum values of the mean NRR (\%) of the total bull population in the AI center in the production years 2010 to 2015 are presented in the last column. 
production period. All bulls were kept under standard conditions of feeding and management. The classification of the selected bulls and their fertility data are presented in Table 1.

Semen Collection and Processing. The cryopreserved sperm samples examined in the study originated from the regular semen collection schedule of the AI center. Semen was collected using a disposable tube attached to a pre-warmed $\left(38^{\circ} \mathrm{C}\right)$ sterile artificial vagina and a dummy cow or a bull. Ejaculates were immediately evaluated in terms of ejaculate volume, sperm concentration, and motility with phase-contrast microscopy (at 100× magnification). Ejaculates with volume $\geq 2 \mathrm{~mL}$, sperm concentration $\geq 500 \times 10^{6}$ sperm $/ \mathrm{mL}$, and motility $\geq 70 \%$ were further processed and cryopreserved.

Semen was extended with Andromed or Triladyl extender (Minitüb GmbH, Tiefenbach, Germany) depending on the production year. Sperm was packaged in 0.25 -mL French straws (IMV Technologies, L'Aigle, France) and equilibrated at $4^{\circ} \mathrm{C}$ for $24 \mathrm{~h}$. Freezing was performed using a computer-assisted freezing chamber (TYP Digitcool 5300 3T, Fa., IMV Technologies) with a rate of temperature decrease of $4.7^{\circ} \mathrm{C} / \mathrm{min}$ to $-10^{\circ} \mathrm{C}$, $29^{\circ} \mathrm{C} / \mathrm{min}$ to $-68^{\circ} \mathrm{C}$, and $10^{\circ} \mathrm{C} / \mathrm{min}$ to $-140^{\circ} \mathrm{C}$. Right afterward, frozen semen was stored in liquid nitrogen $\left(-196^{\circ} \mathrm{C}\right)$.

Preparation of Semen Before Analysis. Three straws from each ejaculate were thawed in a water bath $\left(38^{\circ} \mathrm{C}, 30 \mathrm{~s}\right)$ and pooled in a pre-warmed $\left(38^{\circ} \mathrm{C}\right) 1.5$ $\mathrm{mL}$ laboratory tube. Pooled samples were further assessed with computer-assisted sperm analysis (CASA) and flow cytometry immediately after thawing $\left(\begin{array}{ll}\mathbf{0} & \mathbf{h}\end{array}\right)$ and after $3 \mathrm{~h}(\mathbf{3} \mathbf{h})$ of incubation at $38^{\circ} \mathrm{C}$ in $5 \% \mathrm{CO}_{2}$ humidified atmosphere. Procedures of semen analysis were identical for samples examined at 0 and $3 \mathrm{~h}$ unless mentioned otherwise.

\section{Computer-Assisted Sperm Analysis}

Sperm motility and kinematics were assessed using an IVOS II CASA system driven by software version 1.10.1 (Hamilton Thorne Inc., Beverly, MA). A prewarmed $\left(38^{\circ} \mathrm{C}\right) 20-\mu \mathrm{m}$-deep 4-chamber Leja slide (IMV Technologies) was filled with $6 \mu \mathrm{L}$ of semen, and a minimum of 1,000 cells was analyzed in at least 8 randomly selected fields with 30 frames acquired per field at a frame rate of $60 \mathrm{~Hz}$. Sperm with straightness $\geq 70 \%$ and average path velocity $\geq 50 \mu \mathrm{m} / \mathrm{s}$ were considered progressively motile, whereas sperm with average path velocity $\geq 50 \mu \mathrm{m} / \mathrm{s}$ were classified as rapidly motile. In each sample the percentage of total motile (total motility), progressively motile (progressive motility), and rapidly motile sperm (rapid motility) was recorded.

\section{Flow Cytometric Analyses}

Chemicals and Reagents. The chemicals used for the preparation of Tyrode's solution, Tris-NaCl-EDTA buffer (0.01 $M$ Tris, $0.15 M \mathrm{NaCl}, 1 \mathrm{~m} M$ EDTA, pH 7.4), acid detergent solution $(0.15 \mathrm{M} \mathrm{NaCl}, 0.08 \mathrm{~N} \mathrm{HCl}, 0.1 \%$ Triton-X 100, $\mathrm{pH}$ 1.2), acridine orange (AO) staining buffer $\left(0.2 \mathrm{M} \mathrm{Na}_{2} \mathrm{HPO}_{4}, 1 \mathrm{~m} M\right.$ EDTA, $0.15 \mathrm{M} \mathrm{NaCl}$, $0.1 M$ citric acid, $\mathrm{pH}$ 6.0), as well as PI, were purchased from Sigma-Aldrich Co. (Buchs, Switzerland). The fluorochromes CELLTRACE Calcein Violet AM, Fluo$4 \mathrm{AM}$ and $1,1^{\prime}, 3,3,3^{\prime}, 3^{\prime}$-hexamethylindodicarbocyanine iodide [MITOPROBE $\left.\operatorname{DiIC}_{1}(5)\right]$ were obtained from Thermo Fisher Scientific Inc. (Waltham, CA), and AO and PE-PNA were purchased from Polysciences Europe GmbH (Eppelheim, Germany) and GeneTex Inc. (Irvine, $\mathrm{CA}$ ), respectively.

The purchased fluorescent probes were diluted and used for sperm staining in form of working solutions as described here: $25 \mu \mathrm{g}$ of calcein violet $\mathrm{AM} / 52 \mu \mathrm{L}$ of dimethyl sulfoxide (DMSO; $1.21 \mu M$ ); $10 \mathrm{mg}$ of PI/5 $\mathrm{mL}$ of double-distilled water $(2.99 \mathrm{mM} \mathrm{PI}) ; 1 \mathrm{mg} / \mathrm{mL}$ of PE-PNA; $50 \mu \mathrm{g}$ of Fluo-4 AM/225 $\mu \mathrm{L}$ of DMSO $(2$ $\mu M) ; 10 \mu M \operatorname{DiIC}_{1}(5)$ in DMSO $(0.015 \mu M)$.

Sperm Chromatin Structure Assay. The fluorochrome(s), the configuration of the instrument, and the data processing approach used to perform the sperm chromatin structure assay (SCSA) are described in the Supplemental File S1 (https://doi.org/10 .3168/jds.2019-16572) following the recommendations of Lee et al. (2008). The SCSA was performed to evaluate the susceptibility of sperm to acid-induced DNA fragmentation at 0 and $3 \mathrm{~h}$, using a Coulter Epics XL flow cytometer driven by EXPO32 ADC XL 4 Color software (Beckman Coulter Inc., Krefeld, Germany). In short, $400 \mu \mathrm{L}$ of acid detergent solution was added to $200 \mu \mathrm{L}$ of semen previously diluted with Tris-NaClEDTA buffer to a final concentration of 1 to $2 \times 10^{6}$ sperm $/ \mathrm{mL}$. Following the mixing of the sample for 30 $\mathrm{s}, 1.2 \mathrm{~mL}$ of $\mathrm{AO}$ staining solution $(6.0 \mu \mathrm{g}$ of $\mathrm{AO} / \mathrm{mL}$ of AO staining buffer) was added and stained samples were assessed by flow cytometry after exactly $3 \mathrm{~min}$. Cells were excited by a 488-nm argon laser and the emitted green and red fluorescence was captured by means of a 525/20 BP (FL1) and a 620/15 BP (FL3) filter, respectively. In total, 10,000 cells were analyzed for each sample at a flow rate of 200 cells/s. Flow cytometric data analysis was performed using the 4.07.0005 version of FCS Express 4 Flow Cytometry Research Edition software (De Novo Software, Glendale, CA). The mean value and standard deviation of the DNA fragmentation index (DFI) as well as the percentage of cells with high DFI (\%DFI) were computed as previously described by Evenson and Jost (2001; please refer 
to Supplemental File S1 at https://doi.org/10.3168/jds .2019-16572 for further details).

Multicolor Assay. The fluorochrome(s), the configuration of the instrument and the data processing approach used to perform the multicolor assay are described in the Supplemental File S2 (https://doi .org/10.3168/jds.2019-16572) following the recommendations of Lee et al. (2008). The multicolor assay was performed using the CytoFLEX Flow Cytometer V5-B5-R3 operated by the CytExpert Software for CytoFLEX version 2.1 (Beckman Coulter Inc., Nyon, Switzerland; https://www.beckmancoulter.com/). The flow cytometer included 5 channels from the violet ( 405 $\mathrm{nm})$ laser, 5 channels from the blue $(488 \mathrm{~nm})$ laser, and 3 channels from the red $(638 \mathrm{~nm})$ laser. The violet, blue, and red solid-state diode lasers operated with a power of 80,50 , and $50 \mathrm{~mW}$, respectively. Flow rate was set to $60 \mu \mathrm{L} / \mathrm{min}$ and 500 to 1,000 events/s; for each sample 10,000 cells were analyzed. A forward scatter area versus forward scatter height density plot was used to exclude doublets; doublet exclusion was further verified through a side scatter area versus side scatter height plot (Supplemental File S2; https://doi.org/10 .3168/jds.2019-16572).

A fluorescent panel consisting of calcein violet AM, PI, PE-PNA, Fluo-4 AM, and $\mathrm{DiIC}_{1}(5)$ was employed for the simultaneous evaluation of intracellular esterase activity, plasma membrane integrity, acrosomal status, intracellular $\mathrm{Ca}^{2+}$ levels, and MMP of sperm, respectively. Calcein violet AM was used as an indicator of intracellular esterase activity and, therefore, a marker for cell viability. After excitation with the violet laser, esterase-active cells emitted violet fluorescence that was detected through a $450 / 45$ band-pass filter. The membrane impermeant dye PI was used to distinguish between cells with intact or defect plasma membrane based on the emission or not of red fluorescence (detected by the $690 / 50$ band-pass filter) after excitation with the blue laser, respectively. Acrosomal status was evaluated using PE-PNA, a lectin that binds to the outer acrosomal membrane of sperm. In contrast to sperm with nonstained acrosome, cells with defect acrosome emitted orange fluorescence (detected through the 585/42 band-pass filter) following excitation with the blue laser. The intensity of green fluorescence emitted from Fluo4 AM-stained cells corresponds to the concentration of free intracellular $\mathrm{Ca}^{2+}\left(\left[\mathbf{C a}^{2+}\right]_{\mathrm{i}}\right)$; following excitation with the blue laser, sperm with low or high $\left[\mathrm{Ca}^{2+}\right]_{\mathrm{i}}$ emitted green fluorescence of low or high intensity, respectively, that was captured through a 525/40 band-pass filter. The cationic dye $\operatorname{DiIC}_{1}(5)$ was included in the fluorescent panel for the detection of sperm sub-populations with different MMP. After excitation with the red laser, sperm with high MMP emitted intense signal in the far-red region, whereas low-MMP sperm emitted light red fluorescence; red fluorescence was captured by the $660 / 20$ band-pass filter.

For the examination of each sperm sample with the multicolor assay, sperm was diluted to a concentration of $1.2 \times 10^{6}$ sperm $/ \mathrm{mL}$ with Tyrode's solution at a final volume of $244.75 \mu \mathrm{L}$ in a $250-\mu \mathrm{L}$ reaction well of a 96-well plate. Just before the performance of the assay, the fluorescent probes were combined in a master mix solution consisting of $0.375 \mu \mathrm{L}$ of calcein violet $\mathrm{AM}, 1.5$ $\mu \mathrm{L}$ of PI, $0.5 \mu \mathrm{L}$ of PE-PNA, $2.5 \mu \mathrm{L}$ of Fluo- $4 \mathrm{AM}$, and $0.375 \mu \mathrm{L}$ of $\mathrm{DiIC}_{1}(5)$ per reaction well. Thus, $5.25 \mu \mathrm{L}$ of master mix was added to each reaction well. After 15 min of incubation at $38^{\circ} \mathrm{C}$, sperm was analyzed by flow cytometry; at this time Fluo-4 AM included in the staining solution was allowed to load into the sperm cells.

The present study focused on sperm sub-populations simultaneously exhibiting 2 or more of the following features:

- sperm with high esterase activity, exhibiting intense violet fluorescence after staining with calcein violet $\left(\mathbf{C}_{\text {pos }}\right)$;

- sperm with intact plasma membrane, not stained with PI ( $\left.\mathbf{P I}_{\text {neg }}\right)$;

- sperm not stained with PE-PNA (PNA ${ }_{\text {neg }}$ );

- sperm with low $\left[\mathrm{Ca}^{2+}\right]_{\mathrm{i}}$, exhibiting Fluo-4 AM green fluorescence of low intensity $\left(\mathbf{F}_{\text {neg }}\right)$; and

- sperm with high MMP, exhibiting intense $\mathrm{DiIC}_{1}(5)$ red fluorescence $\left(\mathbf{M}_{\text {pos }}\right)$.

In total, 18 sperm sub-populations were identified using the multicolor assay, as described in Table 2.

\section{Statistical Analysis}

Statistical analysis of the experimental data was performed using the $\mathrm{R}$ version 3.1.3 language for statistical computing (The R Development Core Team, 2016). Values of CASA and SCSA traits as well as the $\%$ relative size of 18 sperm sub-populations determined with the multicolor assay (MC traits) were used as input for the statistical analysis; in total, 91 ejaculates collected from $\mathrm{n}=20$ bulls were examined.

Correlations between NRR of each bull and sperm traits were assessed calculating the Spearman's correlation coefficient $\left(\mathbf{r}_{\mathrm{s}}\right)$ at the 0.05 significance level. In particular, the mean value of each sperm trait was calculated across the ejaculates of each bull; values of $\mathrm{r}_{\mathrm{s}}$ were then computed to describe the correlation between NRR and sperm traits at the level of bull. 
Table 2. Annotation of sperm sub-populations identified with the multicolor assay ${ }^{1}$

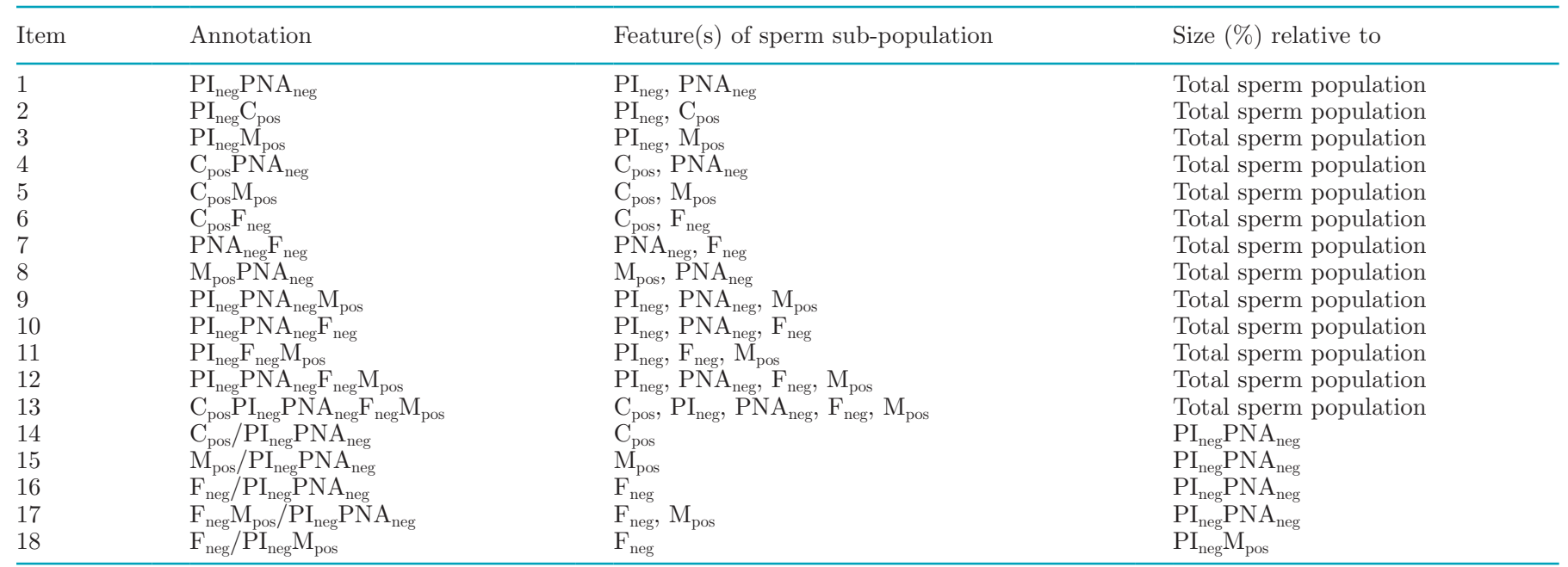

${ }^{1}$ The $\%$ relative size of sperm sub-populations exhibiting 2 or more of the following features was used as input for statistical analysis: high esterase activity $\left(\mathrm{C}_{\text {pos }}\right)$, intact plasma membrane $\left(\mathrm{PI}_{\text {neg }}\right)$, unstained acrosome $\left(\mathrm{PNA}_{\text {neg }}\right)$, low intracellular Ca ${ }^{2+}$ levels $\left(\mathrm{F}_{\text {neg }}\right)$, and high mitochondrial membrane potential $\left(\mathrm{M}_{\mathrm{pos}}\right)$.

Differences of MC traits (at 0 and $3 \mathrm{~h}$ ) between $\mathrm{HF}$ and LF bulls were assessed by means of linear mixedeffects models. Each one of the $18 \mathrm{MC}$ traits was modeled as a linear function of the fixed effect of fertility (2-level factor; LF, HF group), incubation (2-level factor; $0 \mathrm{~h}, 3 \mathrm{~h}$ ), and their interaction term (fertility $\times$ incubation). The effect of ejaculate (nested within bull) was added as a random effect, with a first-order autoregressive covariance structure for a continuous time variable (date of ejaculate collection). The intercept of the line describing the relationship between MC traits and the fertility group was allowed to vary across bulls. Model parameters were estimated using the method of maximum likelihood. Linear mixed-effects modeling was performed using the lme function of the nlme statistical package, while the plot and qqnorm functions were used to visually inspect the distribution of model residuals (Pinheiro et al., 2017).

The random forest (RF) supervised learning method (Breiman, 2001) was performed to identify sperm traits important for the discrimination of ejaculates to 1 of the 2 fertility groups (LF, HF). The RF ensemble uses different bootstrap samples of the original data to construct a set of $\mathrm{n}=$ ntree decision trees. Each decision tree is a flowchart-like model with the aim to reduce the variance of the outcome variable after each branching point (node). At each node one predicting variable (sperm trait) is selected as the optimal classifier (the one that results in the higher possible reduction of data variance) out of a sample of variables. For each tree, the $\%$ error rate of the out-of-bag (OOB) sample data is recorded. The mean OOB error is a method of measuring the prediction error of RF using bootstrap aggregating (bagging) to sub-sample data samples used for training; in this way, an independent validation data set for evaluating the predicting algorithm's efficiency is not needed. The importance of each predictor is evaluated through 2 metrics: the mean decrease in accuracy (MDA) and the mean decrease in Gini index (MDGI). The MDA of each predicting variable expresses the increase in the OOB error rate after randomly permuting the values of the variable; the higher the MDA value of a variable, the more important the variable for the classification of samples. The Gini index is a measure of how each variable contributes to the purity of the nodes of the decision trees. Each time a particular variable is used to split a node, the Gini index for the child nodes is calculated and compared with that of the parent node; variables that result in nodes with higher purity have a higher MGDI value and are considered more important for the classification of samples.

The experimental data were split in 2 data sets, the $0 \mathrm{~h}$ data set and $3 \mathrm{~h}$ data set that consisted of the 18 $\mathrm{MC}$ traits that were determined at 0 and $3 \mathrm{~h}$, respectively. The function randomForest of the statistical package randomForest was used for the analysis of the data (Liaw and Wiener, 2002). Each forest consisted of ntree $=600$ trees, whereas the number of sperm traits randomly sampled as candidate predictors at each node were $m$ try $=\sqrt{p}=\sqrt{18} \cong 4$ (with $p=18$, equal to the number of MC traits). Additionally to the $18 \mathrm{MC}$ traits, a randomly distributed variable (randomV) was added to the 0 and $3 \mathrm{~h}$ data set. Values of randomV were 
randomly generated so as to follow the Gaussian distribution, have an arithmetic mean of zero, and standard deviation equal to the squared mean of the standard errors of the measured sperm traits of the 0 and $3 \mathrm{~h}$ data set, respectively. The introduction of randomV served the interpretation of the results in a relative manner; that is, the predictive value of each MC trait for the classification of sperm samples was compared with that by random (Meier, 2017).

The efficiency of the best performing classifiers derived from the RF analysis was further compared by building their receiving operating characteristic (ROC) curves. For this purpose the true positive rate against the false positive rate of each classifier was plotted using the toolbox of the ROCR statistical package for $\mathrm{R}$ (Sing et al., 2005).

\section{RESULTS}

\section{Descriptive Statistics}

The descriptive statistics (mean, SD, minimum, and maximum values) of sperm traits that were assessed with CASA and flow cytometry (SCSA, multicolor assay) at 0 and $3 \mathrm{~h}$ are presented in Supplemental Table S1 (https://doi.org/10.3168/jds.2019-16572; descriptive measures were computed conditional on fertility group and incubation time). As dictated by the results of the multicolor assay, sperm sub-populations combining 2 desired features appeared to account for more than $50 \%$ of the total sperm population at $0 \mathrm{~h}$; exception to that were $\mathrm{PNA}_{\text {neg }} \mathrm{F}_{\text {neg }}$ sperm as well as $\mathrm{C}_{\text {pos }} \mathrm{F}_{\text {neg }}$ sperm in the LF group that comprised $45.18 \pm 8.09 \%$ and $48.45 \pm 8.68 \%$ of the total sperm population, respectively (Supplemental Table S1, https://doi.org/10 $.3168 /$ jds.2019-16572; Figure 1). The samples examined in our study were selected from a pool of semen batches that had successfully undergone the routine quality control for cryopreserved semen and qualified for commercial distribution. Not surprisingly, the vast majority of samples (88 out of 91) showed $>40 \%$ sperm viability $\left(61.24 \pm 9.83 \% \mathrm{C}_{\text {pos }} \mathrm{PI}_{\text {neg }}\right.$ at $0 \mathrm{~h}$; Supplemental Table S1, https://doi.org/10.3168/jds.2019-16572; Figure 1); the above mentioned threshold for sperm viability (i.e., plasma membrane integrity) has previously been suggested by Vincent et al. (2012) for screening cryopreserved bovine semen before commercial use. According to Vincent et al. (2012) semen batches should also be tested for sperm mitochondrial activity, and ejaculates having less than $40 \%$ sperm with functional mitochondria post-thaw should be discarded; indeed, in our study only 3 out of the 91 examined ejaculates had less than $40 \%$ viable sperm with high MMP as dictated by the $\mathrm{PI}_{\text {neg }} \mathrm{M}_{\text {pos }}$ values at $0 \mathrm{~h}$.
Sperm simultaneously exhibiting 3,4 , or 5 features at 0 and $3 \mathrm{~h}$ accounted for less than half of the total sperm population, with the exception of $\mathrm{PI}_{\text {neg }} \mathrm{PNA}_{\text {neg }} \mathrm{M}_{\text {pos }}$ sperm $(0 \mathrm{~h})$ that exceeded $50 \%$ in both fertility groups $(51.85 \pm 8.81 \%$ and $51.36 \pm 8.87 \%$ for the HF and LF group, respectively; Supplemental Table S1, https://doi .org/10.3168/jds.2019-16572; Figure 1). Remarkably, $\mathrm{M}_{\text {pos }}$ cells comprised more than $90 \%$ of $\mathrm{PI}_{\text {neg }} \mathrm{PNA}_{\text {neg }}$ sperm at $0 \mathrm{~h}\left(94.78 \pm 3.82 \%\right.$ and $\left.93.20 \pm 3.74 \% \mathrm{M}_{\text {pos }}\right)$ $\mathrm{PI}_{\text {neg }} \mathrm{PNA}_{\text {neg }}$ sperm in the HF and LF group, respectively); these values were limited to $84.50 \pm 6.05 \%$ and $85.08 \pm 5.31 \%$ at $3 \mathrm{~h}$, respectively (Supplemental Table S1, https://doi.org/10.3168/jds.2019-16572; Figure 1).

\section{Correlations}

The $\mathrm{r}_{\mathrm{s}}$ coefficients (and the respective $P$-values) describing the correlation between continuous variables (NRR and sperm traits) at 0 and $3 \mathrm{~h}$ are presented in Supplemental Tables S2 and S3, respectively (https:/ /doi.org/10.3168/jds.2019-16572). In brief, significant correlations were observed between $\mathrm{MC}$ and SCSA traits at $0 \mathrm{~h}$, with the sign of $\mathrm{r}_{\mathrm{s}}$ being negative in most cases (Supplemental Table S2). Remarkably, the percentages of $F_{\text {neg }}, M_{\text {pos }}$, and $F_{\text {neg }} M_{\text {pos }}$ sperm within the $\mathrm{PI}_{\text {neg }} \mathrm{PNA}_{\text {neg }}$ population were significantly correlated with \%DFI but not to the mean DFI and standard deviation of DFI (Supplemental Table S2). Similar to the correlations described for the $0 \mathrm{~h}$ data set, most $\mathrm{MC}$ traits (with exception of $\mathrm{C}_{\text {pos }} / \mathrm{PI}_{\text {neg }} \mathrm{PNA}_{\text {neg }}$ and $\mathrm{M}_{\text {pos }} / \mathrm{PI}_{\text {neg }} \mathrm{PNA}_{\text {neg }}$ ) were negatively correlated with the 3 SCSA traits at $3 \mathrm{~h}$ (Supplemental Table S3). However, the standard deviation of DFI did not show any significant correlation with $\mathrm{F}_{\text {neg }} / \mathrm{PI}_{\text {neg }} \mathrm{M}_{\text {pos }}, \mathrm{F}_{\text {neg }} / \mathrm{PI}_{\text {neg }} \mathrm{P}$ $\mathrm{NA}_{\text {neg }}$, and $\mathrm{F}_{\text {neg }} \mathrm{M}_{\text {pos }} / \mathrm{PI}_{\text {neg }} \mathrm{PNA}_{\text {neg }}$ (Supplemental Table $\mathrm{S} 3)$. Interestingly, $\mathrm{C}_{\mathrm{pos}} / \mathrm{PI}_{\text {neg }} \mathrm{PNA}_{\text {neg }}$ was not related to any other MC trait at $0 \mathrm{~h}$ or at $3 \mathrm{~h}(P>0.05$ for all pairwise correlations; Supplemental Tables S2 and $\mathrm{S} 3$, respectively). On the other hand, $\mathrm{M}_{\text {pos }} / \mathrm{PI}_{\text {neg }} \mathrm{PNA}_{\text {neg }}$ was positively correlated with $\mathrm{F}_{\text {neg }} / \mathrm{PI}_{\text {neg }} \mathrm{PNA}_{\text {neg }}\left(\mathrm{r}_{\mathrm{s}}=\right.$ $0.47, P<0.01), \mathrm{F}_{\text {neg }} / \mathrm{PI}_{\text {neg }} \mathrm{M}_{\text {pos }}\left(\mathrm{r}_{\mathrm{s}}=0.53, P<0.01\right)$, and $\mathrm{F}_{\text {neg }} \mathrm{M}_{\text {pos }} / \mathrm{PI}_{\text {neg }} \mathrm{PNA}_{\text {neg }}\left(\mathrm{r}_{\mathrm{s}}=0.47, P<0.01\right)$ at 0 h (Supplemental Table S2). At $3 \mathrm{~h}, \mathrm{M}_{\text {pos }} / \mathrm{PI}_{\text {neg }} \mathrm{PNA}_{\text {neg }}$ exhibited a weak $\left(\left|\mathrm{r}_{\mathrm{s}}\right| \leq 0.25\right)$ to moderate $\left(0.25<\left|\mathrm{r}_{\mathrm{s}}\right|\right.$ $\leq 0.50$ ) correlation with several MC traits but was not significantly related to any CASA or SCSA parameter (Supplemental Table S3). Values of NRR were significantly correlated with 7 out of $18 \mathrm{MC}$ parameters determined at $0 \mathrm{~h}$ (Supplemental Table S2). Among all sperm traits assessed at $0 \mathrm{~h}, \mathrm{~F}_{\text {neg }} / \mathrm{PI}_{\text {neg }} \mathrm{M}_{\text {pos }}$ and $\mathrm{F}_{\text {neg }} /$ $\mathrm{PI}_{\text {neg }} \mathrm{PNA}_{\text {neg }}$ were the ones to show the strongest correlation with NRR $\left(\mathrm{r}_{\mathrm{s}}=0.64, P<0.01\right.$ and $\mathrm{r}_{\mathrm{s}}=0.58, P$ $<0.01$, respectively), followed by $\mathrm{F}_{\text {neg }} \mathrm{M}_{\text {pos }} / \mathrm{PI}_{\text {neg }} \mathrm{PNA}_{\text {neg }}$ and \%DFI $\left(\mathrm{r}_{\mathrm{s}}=0.52, P<0.01\right.$ and $\mathrm{r}_{\mathrm{s}}=-0.52, \stackrel{P}{P}$ 
$<0.01$, respectively; Supplemental Table S2). At $3 \mathrm{~h}$, \%DFI exhibited the strongest correlation to NRR $\left(\mathrm{r}_{\mathrm{s}}=\right.$ $-0.58, P<0.01$; Supplemental Table S2).

\section{Mixed-Effects Linear Models}

The significance levels of the Wald tests for the fixed effects of fertility, incubation, and their interaction term (fertility $\times$ incubation) on the MC traits are shown in Table 3; model parameters are presented in
Supplemental Table S4 (https://doi.org/10.3168/jds .2019-16572). As indicated by the negative sign of the b coefficients in Supplemental Table S4, incubation adversely affected all MC traits $(P<0.01$ in all cases; Table 3 and Supplemental Table S4), except for $\mathrm{C}_{\mathrm{pos}} /$ $\mathrm{PI}_{\text {neg }} \mathrm{PNA}_{\text {neg }}(\mathrm{b}=-1.39 \pm 0.88, P=0.12$; Supplemental Table S4) and $\mathrm{F}_{\text {neg }} / \mathrm{PI}_{\text {neg }} \mathrm{M}_{\text {pos }}(\mathrm{b}=-1.64 \pm 1.09, P$ $=0.14$; Supplemental Table S4). On the other hand, the effect of fertility on the overall values of MC traits was not proven significant (Table 3), with exception

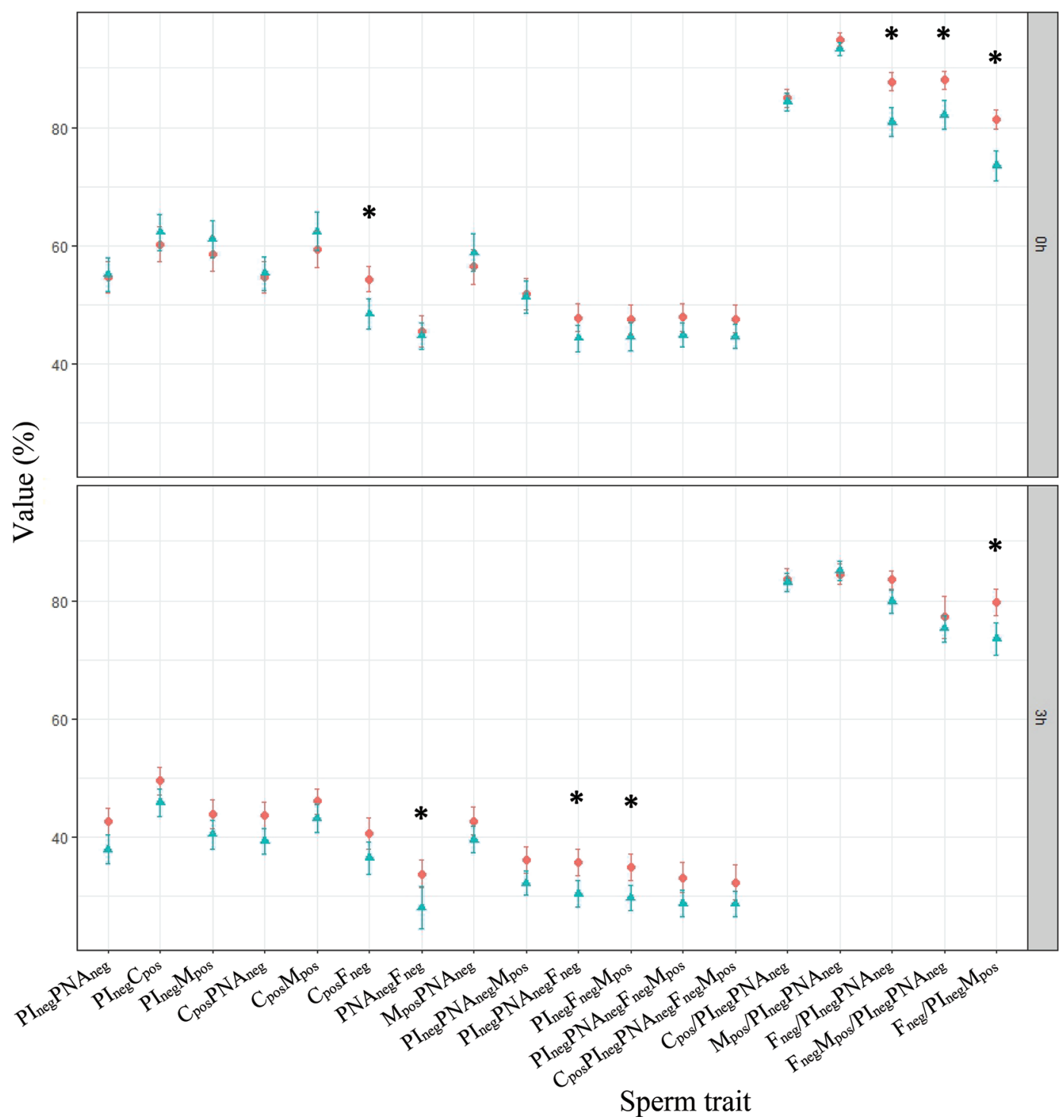

Figure 1. The percentage of sperm showing a combination of 2 or more of the following characteristics was evaluated in 91 cryopreserved ejaculates collected from 10 high-fertility (red $\bullet$ ) and 10 low-fertility (blue $\mathbf{\Delta}$ ) Holstein-Friesian bulls using multicolor flow cytometry: high esterase activity $\left(\mathrm{C}_{\mathrm{pos}}\right)$, intact plasma membrane $\left(\mathrm{PI}_{\text {neg }}\right)$, unstained acrosome $\left(\mathrm{PNA}_{\text {neg }}\right)$, low intracellular $\mathrm{Ca}^{2+}$ levels $\left(\mathrm{F}_{\text {neg }}\right)$, and high mitochondrial membrane potential $\left(\mathrm{M}_{\mathrm{pos}}\right)$. The relative size of each sperm sub-population was computed in relation to the total sperm population examined; the $\%$ size of sperm sub-populations including a slash (/) was calculated relative to the super-ordinary population described after the slash symbol. Ejaculates were tested immediately $(0 \mathrm{~h})$ and after a 3-h incubation $(3 \mathrm{~h})$ post-thaw. Points (bullets, triangles) and error bars represent the mean value and the SEM of each trait, respectively. Least squares means of sperm traits were computed for the factor combination fertility $\times$ incubation; significant between-group differences within each incubation time point are flagged with an asterisk $\left(^{*}\right)$. 
Table 3. Significance levels of Wald tests for the fixed effect of fertility (high fertility, low fertility), incubation ( 0 and $3 \mathrm{~h}$ post-thaw), and the interaction term fertility $\times$ incubation on the traits of 91 cryopreserved bovine ejaculates

\begin{tabular}{|c|c|c|c|c|}
\hline \multirow[b]{2}{*}{ Item } & \multirow[b]{2}{*}{ Sperm trait } & \multicolumn{3}{|c|}{ Fixed effect } \\
\hline & & Fertility & Incubation & Fertility $\times$ incubation \\
\hline 1 & $\mathrm{PI}_{\text {neg }} \mathrm{PNA}_{\text {neg }}$ & & $* *$ & $* *$ \\
\hline 2 & $\mathrm{PI}_{\text {neg }} \mathrm{C}_{\text {pos }}$ & & $* *$ & $* *$ \\
\hline 3 & $\mathrm{PI}_{\mathrm{neg}} \mathrm{M}_{\mathrm{pos}}$ & & $* *$ & $* *$ \\
\hline 4 & $\mathrm{C}_{\text {pos }} \mathrm{PNA}_{\text {neg }}$ & & $* *$ & $* *$ \\
\hline 5 & $\mathrm{C}_{\mathrm{pos}} \mathrm{M}_{\mathrm{pos}}$ & & $* *$ & $* *$ \\
\hline 6 & $\mathrm{C}_{\text {pos }} \mathrm{F}_{\text {neg }}$ & * & $* *$ & \\
\hline 7 & $\mathrm{PNA}_{\text {neg }} \mathrm{F}_{\mathrm{neg}}$ & & ** & * \\
\hline 8 & $\mathrm{M}_{\text {pos }} \mathrm{PNA}_{\text {neg }}$ & & $* *$ & $* *$ \\
\hline 9 & $\mathrm{PI}_{\text {neg }} \mathrm{PNA}_{\text {neg }} \mathrm{M}_{\text {pos }}$ & & $* *$ & $*$ \\
\hline 10 & $\mathrm{PI}_{\text {neg }} \mathrm{PNA}_{\text {neg }} \mathrm{F}_{\text {neg }}$ & & $* *$ & \\
\hline 11 & $\mathrm{PI}_{\text {neg }} \mathrm{F}_{\text {neg }} \mathrm{M}_{\text {pos }}$ & & $* *$ & \\
\hline 12 & $\mathrm{PI}_{\text {neg }} \mathrm{PNA}_{\text {neg }} \mathrm{F}_{\text {neg }} \mathrm{M}_{\text {pos }}$ & & $* *$ & \\
\hline 13 & $\mathrm{C}_{\text {pos }} \mathrm{PI}_{\text {neg }} \mathrm{PNA}_{\text {neg }} \mathrm{F}_{\text {neg }} \mathrm{M}_{\text {pos }}$ & & $* *$ & \\
\hline 14 & $\mathrm{C}_{\text {pos }} / \mathrm{PI}_{\text {neg }} \mathrm{PNA}_{\text {neg }}^{-}$ & & & \\
\hline 15 & $\mathrm{M}_{\text {pos }} / \mathrm{PI}_{\text {neg }} \mathrm{PNA}_{\text {neg }}$ & & $* *$ & \\
\hline 16 & $\mathrm{~F}_{\text {neg }} / \mathrm{PI}_{\text {neg }} \mathrm{PNA}_{\text {neg }}$ & * & $* *$ & $*$ \\
\hline 17 & $\mathrm{~F}_{\text {neg }} \mathrm{M}_{\text {pos }} / \mathrm{PI}_{\text {neg }} \mathrm{PNA}_{\text {neg }}$ & & $* *$ & \\
\hline 18 & $\mathrm{~F}_{\text {neg }} / \mathrm{PI}_{\text {neg }} \mathrm{M}_{\text {pos }}$ & $*$ & & \\
\hline
\end{tabular}

${ }^{1}$ The percentage of sperm showing a combination of 2 or more of the following characteristics was evaluated through multicolor flow cytometry: high esterase activity $\left(\mathrm{C}_{\text {pos }}\right)$, intact plasma membrane $\left(\mathrm{PI}_{\text {neg }}\right)$, unstained acrosome $\left(\mathrm{PNA}_{\text {neg }}\right)$, low intracellular $\mathrm{Ca}^{2+}$ levels $\left(\mathrm{F}_{\text {neg }}\right)$, and high mitochondrial membrane potential $\left(\mathrm{M}_{\text {pos }}\right)$. The relative size of each sperm sub-population was computed in relation to the total sperm population examined; the $\%$ size of sperm sub-populations including a slash $(/)$ was calculated relative to the super-ordinary population described after the slash symbol.

${ }^{*} P<0.05 ;{ }^{* *} P<0.01$; empty cells denote $P>0.05$.

of $\mathrm{C}_{\text {pos }} \mathrm{F}_{\text {neg }}, \mathrm{F}_{\text {neg }} / \mathrm{PI}_{\text {neg }} \mathrm{PNA}_{\text {neg }}$, and $\mathrm{F}_{\text {neg }} / \mathrm{PI}_{\text {neg }} \mathrm{M}_{\text {pos }}$ that were lower in LF compared with HF bulls (Supplemental Table S4). The effect of fertility on the response of MC traits to incubation stress was variable (Table 3 ). With exception of $\mathrm{C}_{\text {pos }} \mathrm{F}_{\text {neg }}(\mathrm{b}=1.73 \pm 1.70, P=0.30$; Supplemental Table S4), LF bulls showed a more pronounced decrease of their 2-feature MC traits between 0 and $3 \mathrm{~h}$ when compared with the HF bulls $(\mathrm{b}=<0$, $P<0.05 ;$ Supplemental Table S4). Interestingly, the effect of incubation on $\mathrm{F}_{\text {neg }} / \mathrm{PI}_{\text {neg }} \mathrm{PNA}_{\text {neg }}$ was not that severe in the LF compared with the HF group $(b=3.14$ $\pm 1.49, P=0.04$; Supplemental Table S4). The MC traits that showed significant fertility group-dependent differences of their least squares means values within each incubation time point are flagged in Figure 1.

\section{Random Forests}

The most interesting output of the RF analysis was the estimated values of the OOB error rate (Table 4) and the variable importance plots (Figure 2). The OOB error rate slightly changed for each new run of RF; thus, the OOB error rates are an estimate derived from a series of $\mathrm{OOB}$ error rate values. The estimated $\mathrm{OOB}$ error rate was 34.07 and $30.77 \%$ when RF were applied to the $0 \mathrm{~h}$ and the $3 \mathrm{~h}$ data set, respectively (Table 4 ).
This implies that approximately two-thirds of ejaculates could be accurately assigned to their fertility group. As shown in Table 4 , the classification error rate at $0 \mathrm{~h}$ was higher for samples of the LF group compared with the HF group (32.61 and $35.55 \%$ for the HF and LF group, respectively). A similar but more pronounced pattern was observed at the $3 \mathrm{~h}$ data set, with a classification error rate of 21.74 and $40.00 \%$ for the HF and LF group, respectively (Table 4). As dictated by the classification error rates described in Table 4, the predictability of fertility improved for the HF ejaculates at $3 \mathrm{~h}$, but this was not the case for LF ejaculates.

The importance of each MC trait for the prediction of the fertility group was quantified using the measures MDGI and MDA. Evaluating the MDA values demonstrated in Figure 2A, a distinct break was already visible after the first $\mathrm{MC}$ trait $\mathrm{F}_{\text {neg }} / \mathrm{PI}_{\text {neg }} \mathrm{M}_{\text {pos }}$. Indeed, $\mathrm{F}_{\text {neg }} / \mathrm{PI}_{\text {neg }} \mathrm{M}_{\text {pos }}$ outstood as the MC trait with the highest MDGI and MDA at $0 \mathrm{~h}$ (Figure 2A); MC traits with lower MDGI and MDA values were considered of lesser importance for the classification of samples. When applying $\mathrm{RF}$ to the $3 \mathrm{~h}$ data set, $\mathrm{F}_{\text {neg }} / \mathrm{PI}_{\text {neg }} \mathrm{M}_{\text {pos }}$ was still the MC trait with the highest MDGI and MDA values; $\mathrm{MC}$ traits scoring lower than $\mathrm{F}_{\text {neg }} / \mathrm{PI}_{\text {neg }} \mathrm{M}_{\text {pos }}$ formed a block with none of them outstanding (Figure 2B). All $\mathrm{MC}$ traits at 0 and $3 \mathrm{~h}$ scored better than randomV 
Table 4. Confusion matrix of the performance of a random forest binary classifier that included 18 sperm traits, assessed in 91 cryopreserved bovine ejaculates with multicolor flow cytometry immediately $(0 \mathrm{~h})$ and after 3 -h incubation $(3 \mathrm{~h})$ post-thaw, for the classification of samples in 2 fertility groups (high fertility, low fertility $)^{1}$

\begin{tabular}{lcccc}
\hline Item & $\begin{array}{c}\text { Predicted: } \\
\text { high fertility }\end{array}$ & $\begin{array}{c}\text { Predicted: } \\
\text { low fertility }\end{array}$ & $\begin{array}{c}\text { Classification } \\
\text { error rate (\%) }\end{array}$ & $\begin{array}{c}\text { OOB error } \\
\text { rate (\%) }\end{array}$ \\
\hline $\begin{array}{l}\text { Data set: sperm traits at 0 h } \\
\text { Actual: high fertility }\end{array}$ & 31 & 15 & 32.61 & 34.07 \\
$\begin{array}{l}\text { Actual: low fertility } \\
\text { Data set: sperm traits at } 3 \mathrm{~h}\end{array}$ & 16 & 29 & 35.55 & \\
$\quad \begin{array}{l}\text { Actual: high fertility } \\
\text { Actual: low fertility }\end{array}$ & 36 & 10 & 21.74 & 30.77 \\
\hline
\end{tabular}

${ }^{1}$ For each data set $(0 \mathrm{~h}, 3 \mathrm{~h}), 91$ predictions were made; the classification error (\%) within each fertility group as well as the out-of-bag (OOB) error rate (\%) of the random forests algorithm were computed separately for each data set.

on MDA, but randomV had higher MDGI values compared with 12 and 7 out of $18 \mathrm{MC}$ traits at 0 and $3 \mathrm{~h}$, respectively (Figure $2 \mathrm{~A}$ and $2 \mathrm{~B}$, respectively). The MC traits scoring lower than randomV were not expected to predict fertility better than just by random.

The outcome of variable importance plots (Figure 2) showed that bull fertility could be predicted by a model based on only one $\mathrm{MC}$ trait (i.e., $\mathrm{F}_{\text {neg }} / \mathrm{PI}_{\text {neg }} \mathrm{M}_{\text {pos }}$ ). To improve the performance of the prediction algorithm, several CASA and SCSA traits were stepwise combined with $\mathrm{F}_{\text {neg }} / \mathrm{PI}_{\text {neg }} \mathrm{M}_{\text {pos }}$, and $\mathrm{RF}$ were subsequently applied (data not shown). The addition of \%DFI at $0 \mathrm{~h}$ improved the OOB error rate to a final value of $24.18 \%$ (with 21.74 and $26.67 \%$ classification error for the HF and LF group, respectively). The OOB error rate of the $3 \mathrm{~h}$ data set could not be further improved by any combination of the $\mathrm{F}_{\text {neg }} / \mathrm{PI}_{\text {neg }} \mathrm{M}_{\text {pos }}(3 \mathrm{~h})$ with other CASA or SCSA traits; however, the deviation in the classification error rate between the $\mathrm{HF}$ and the LF group was reduced by the combination of $\mathrm{F}_{\text {neg }} /$ $\mathrm{PI}_{\text {neg }} \mathrm{M}_{\text {pos }}$ and rapid motility at $3 \mathrm{~h}(30.77 \%$ OOB error rate; 34.78 and $26.67 \%$ classification error rate for the $\mathrm{HF}$ and LF group, respectively). Thus, the ROC curves of the following $4 \mathrm{RF}$ classifiers were built (Figure 3): (a) with $18 \mathrm{MC}$ traits at $0 \mathrm{~h}$ (red curve), (b) with 18 $\mathrm{MC}$ traits at $3 \mathrm{~h}$ (blue curve), (c) $\mathrm{F}_{\text {neg }} / \mathrm{PI}_{\text {neg }} \mathrm{M}_{\text {pos }}$ and $\%$ DFI at $0 \mathrm{~h}$ (orange curve), and (d) $\mathrm{F}_{\text {neg }} / \mathrm{PI}_{\text {neg }} \mathrm{M}_{\text {pos }}$ and rapid motility at $3 \mathrm{~h}$ (green curve). The area under the curve of the above described classifiers was 0.723 , $0.767,0.857$, and 0.751 , respectively. The combination of $\mathrm{F}_{\text {neg }} / \mathrm{PI}_{\text {neg }} \mathrm{M}_{\text {pos }}$ and \%DFI at $0 \mathrm{~h}$ covered the largest area under the curve (Figure 3) and showed the lowest OOB error rate among them.

Linear regression analysis was performed to model the values of NRR as a function of $\mathrm{F}_{\text {neg }} / \mathrm{PI}_{\text {neg }} \mathrm{M}_{\text {pos }}$ and $\%$ DFI at $0 \mathrm{~h}$ (i.e., the combination of sperm quality features that appeared to be the most efficient for the identification of HL and LF bulls with RF). The following model was developed:

$$
\begin{gathered}
\mathrm{NRR}=41.78+\left(0.36 \times \mathrm{F}_{\text {neg }} / \mathrm{PI}_{\text {neg }} \mathrm{M}_{\mathrm{pos}}\right) \\
-(0.89 \times \% \mathrm{DFI}),
\end{gathered}
$$

where $\mathrm{NRR}, \mathrm{F}_{\text {neg }} / \mathrm{PI}_{\text {neg }} \mathrm{M}_{\text {pos }}$, and \%DFI values are expressed as a percentage (\%). The combination of $\mathrm{F}_{\text {neg }} /$ $\mathrm{PI}_{\text {neg }} \mathrm{M}_{\text {pos }}$ and $\%$ DFI at $0 \mathrm{~h}$ described more than $40 \%$ of the NRR variation, with values of the coefficient of determination $\left(\mathrm{R}^{2}\right)$ and the adjusted coefficient of determination (adjusted $\mathrm{R}^{2}$ ) of the above model being 0.466 and 0.454 , respectively $(P<0.01)$. The relation between the predicted and the actual values of NRR is illustrated in Figure 4. An example of a RF decision tree using $\mathrm{F}_{\text {neg }} / \mathrm{PI}_{\text {neg }} \mathrm{M}_{\text {pos }}$ and \%DFI at $0 \mathrm{~h}$ as predictors of the fertility group is presented in Figure 5.

\section{DISCUSSION}

The present study aimed at the multi-parametric characterization of the functional status of cryopreserved semen produced by bulls of high and low fertility. In particular, sperm with structurally intact and functional plasma membrane, intact acrosome, low intracellular $\mathrm{Ca}^{2+}$ levels, and functional mitochondria were targeted by means of a 5-color flow cytometric assay. Thirteen traits representing the percentage of sperm within the ejaculate that simultaneously exhibited 2 or more of the above mentioned qualities were determined. In an attempt to further explore the composition of sub-ordinary sperm populations, the percentage of $\mathrm{C}_{\text {pos}}$, $F_{\text {neg }}, M_{\text {pos }}$, and $F_{\text {neg }} M_{\text {pos }}$ sperm within the $\mathrm{PI}_{\text {neg }} \mathrm{PNA}_{\text {neg }}$ population as well as the fraction of $\mathrm{F}_{\text {neg }}$ sperm within the $\mathrm{PI}_{\text {neg }} \mathrm{M}_{\text {pos }}$ population were determined.

As shown by the analysis of the data, approximately $84 \%$ of $\mathrm{PI}_{\text {neg }} \mathrm{PNA}_{\text {neg }}$ cells showed a high esterase activity at $0 \mathrm{~h}$, with group-dependent differences between bulls being inconsiderable. Despite the decrease of $\mathrm{PI}_{\text {neg }} \mathrm{PNA}_{\text {neg }}$ below $50 \%$ after $3 \mathrm{~h}$ of incubation, still more than $80 \%$ of $\mathrm{PI}_{\text {neg }} \mathrm{PNA}_{\text {neg }}$ sperm exhibited a cal- 
cein violet fluorescent signal. As previously suggested by Petrunkina and Harrison (2013), the employment of calcein violet $\mathrm{AM}$ in the current flow cytometric panel served the purpose of a live-cell stain in combination with PI. Our results showed that esterase activity is a rather stable feature of sperm with structurally intact plasma membrane.

Further analyzing the heterogeneity of $\mathrm{PI}_{\text {neg }} \mathrm{PNA}_{\text {neg }}$ sperm sub-population, more than $90 \%$ of the latter showed an accumulation of the cyanine dye $\operatorname{DiIC}_{1}(5)$ at $0 \mathrm{~h}$, which indicates a high MMP. It is also worth mentioning that $\mathrm{PI}_{\text {neg }} \mathrm{PNA}_{\text {neg }}$ and $\mathrm{M}_{\text {pos }} / \mathrm{PI}_{\text {neg }} \mathrm{PNA}_{\text {neg }}$ values were not significantly correlated at $0 \mathrm{~h}$ or at $3 \mathrm{~h}$. In combination, these findings suggest that high MMP is a consistent attribute of the majority of viable sperm with an unstained acrosome, regardless of the absolute numbers of the latter within the ejaculate. The critical importance of MMP for the cell's functional state and viability has been extensively investigated (Amaral et al., 2013; Zorova et al., 2018). Apart from their welldocumented role in sperm metabolism and motility (Paoli et al., 2011; Ferramosca et al., 2012), mitochondria are also major components of the intrinsic apoptotic pathway in mammalian sperm cells (Hendricks
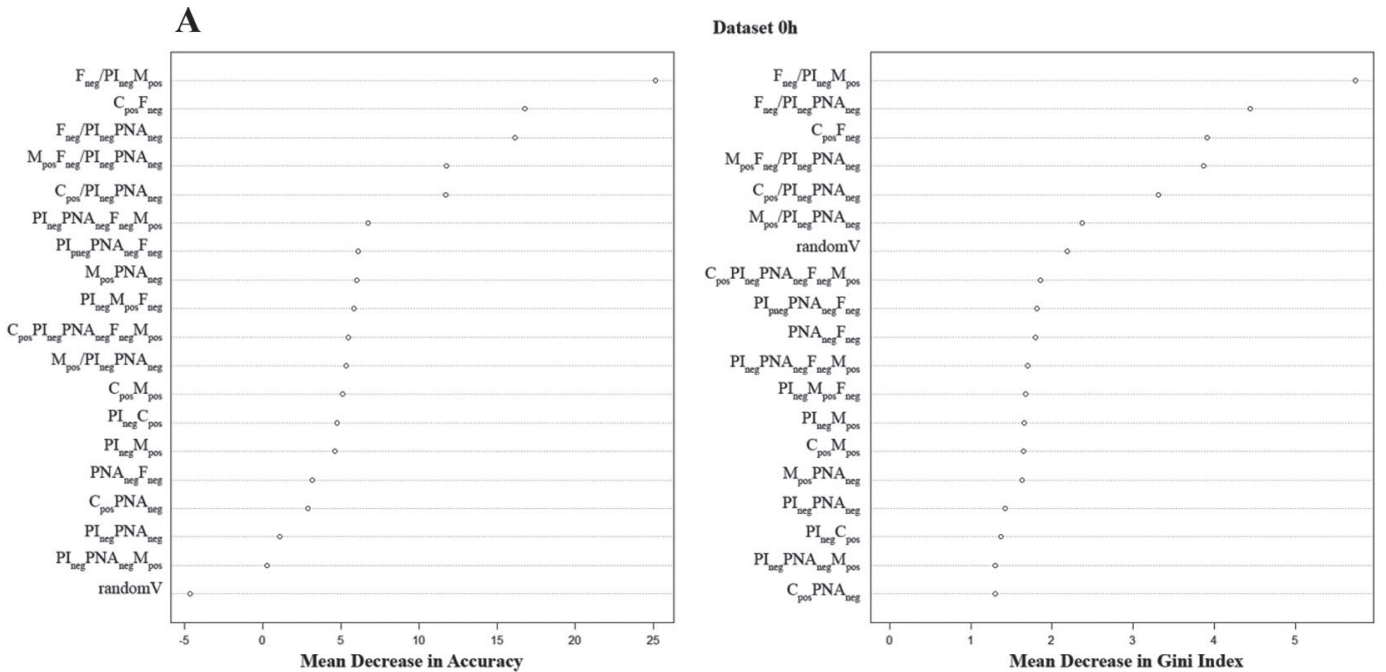

B

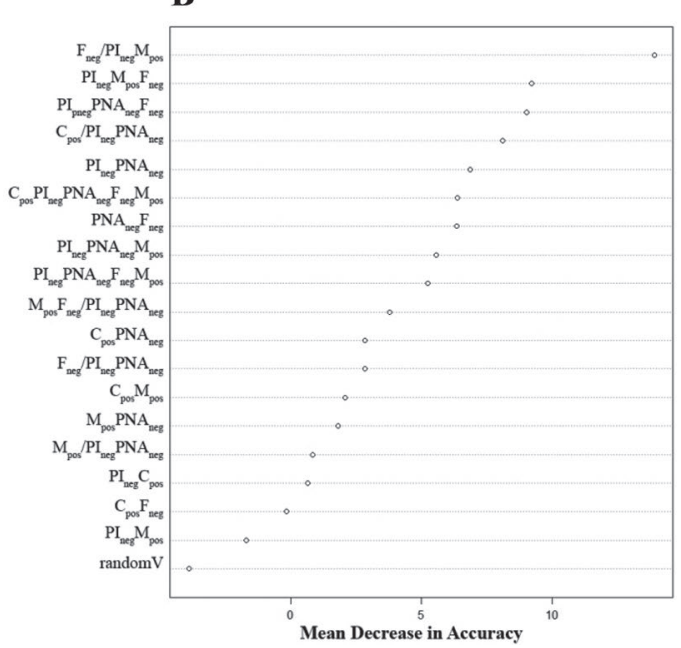

Dataset 3h

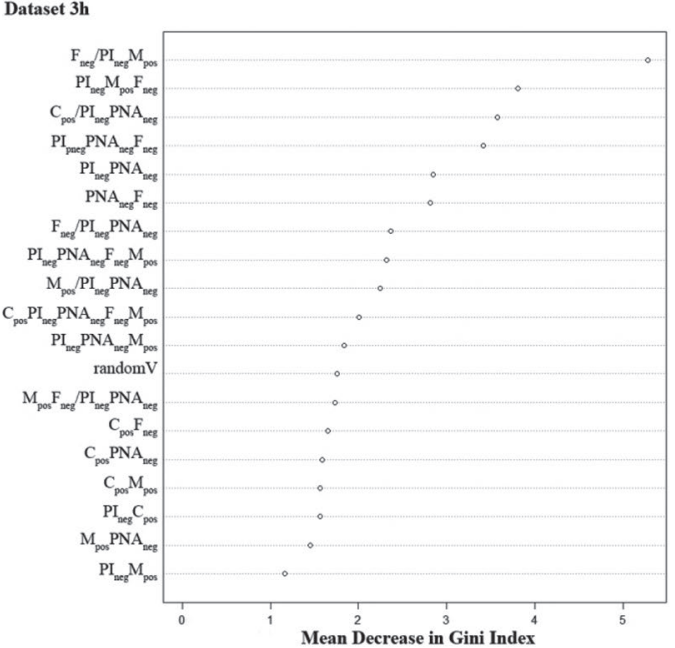

Figure 2. Importance plots of 18 sperm traits assessed in 91 ejaculates produced from 10 high- and 10 low-fertility Holstein-Friesian bulls. Applying the random forest method for the prediction of bull fertility, the predictive value of each sperm trait was expressed as the mean decrease in accuracy and the mean decrease in Gini index after random permutation of its values. The percentage of sperm showing a combination of 2 or more of the following characteristics was evaluated using multicolor flow cytometry: high esterase activity $\left(\mathrm{C}_{\mathrm{pos}}\right)$, intact plasma membrane $\left(\mathrm{PI}_{\text {neg }}\right)$, unstained acrosome $\left(\mathrm{PNA}_{\text {neg }}\right)$, low intracellular $\mathrm{Ca}^{2+}$ levels $\left(\mathrm{F}_{\text {neg }}\right)$, and high mitochondrial membrane potential $\left(\mathrm{M}_{\text {pos }}\right)$. The relative size of each sperm sub-population was computed in relation to the total sperm population examined; the \% size of sperm sub-populations including a slash (/) was calculated relative to the super-ordinary population described after the slash symbol. Ejaculates were tested immediately (0 h) and after a 3 -h incubation $(3 \mathrm{~h})$ post-thaw. The randomly distributed variable randomV followed the Gaussian distribution, with an arithmetic mean of 0 and SD equal to the squared mean of the SE of the 18 sperm traits of the $0 \mathrm{~h}$ and the $3 \mathrm{~h}$ data set, respectively. 
and Hansen, 2009; Kim et al., 2013). In the bull, previous studies have also shown a strong relation between the structural changes of sperm plasma membrane and MMP (Barroso et al., 2006; Bollwein et al., 2008).

As discussed above, the population of $\mathrm{PI}_{\text {neg }} \mathrm{PNA}_{\text {neg }}$ sperm appeared rather homogeneous in terms of mitochondrial function judging from the high values of $\mathrm{M}_{\text {pos }} / \mathrm{PI}_{\text {neg }} \mathrm{PNA}_{\text {neg }}(0 \mathrm{~h})$. This raised questions about the inclusion of a mitochondria-targeting dye in the fluorescent panel, since the information gained from $\operatorname{DiIC}_{1}(5)$ overlapped with this obtained through the combined staining of sperm with PI and PNA. As shown by our results, the percentage of $\mathrm{F}_{\text {neg }}$ sperm within the $\mathrm{PI}_{\text {neg }} \mathrm{P}$ $\mathrm{NA}_{\text {neg }}$ population approached $85 \%$ at $0 \mathrm{~h}$. Subsequently, when gating $\mathrm{PI}_{\text {neg }} \mathrm{PNA}_{\text {neg }}$ sperm for an additional attribute (i.e., high MMP), the values of $\mathrm{F}_{\text {neg }} \mathrm{M}_{\text {pos }} / \mathrm{PI}_{\text {neg- }}$ $\mathrm{PNA}_{\text {neg }}(0 \mathrm{~h})$ were close to those of $\mathrm{F}_{\text {neg }} / \mathrm{PI}_{\text {neg }} \mathrm{PNA}_{\text {neg }}$. In accordance with this observation, the size of sperm populations determined through the signal of $4\left(\mathrm{PI}_{\text {neg- }}\right.$ $\left.\mathrm{PNA}_{\text {neg }} \mathrm{F}_{\text {neg }} \mathrm{M}_{\text {pos }}\right)$ or $5\left(\mathrm{C}_{\text {pos }} \mathrm{PI}_{\text {neg }} \mathrm{PNA}_{\text {neg }} \mathrm{F}_{\text {neg }} \mathrm{M}_{\text {pos }}\right)$ colors was similar to that of the 3-color population $\mathrm{PI}_{\text {neg }} \mathrm{P}$ $\mathrm{NA}_{\text {neg }} \mathrm{F}_{\text {neg }}(46.45 \pm 7.43 \%, 46.17 \pm 7.45 \%$, and 46.12 $\pm 7.82 \%$ at $0 \mathrm{~h}$, respectively). Based on these findings, the informative value of a mitochondria-targeting dye in the current flow cytometric panel was further challenged. On the other hand, it was apparent that the expansion of the commonly used PI/PNA dual staining by even one color (e.g., an intracellular calcium indicator) could already lead to more informative characterization of the examined sperm.

To further investigate the dynamics of different subpopulations, sperm were subjected to 3 -h incubation at $38^{\circ} \mathrm{C}$. Apart from the expected incubation-mediated decrease of $\mathrm{PI}_{\text {neg }} \mathrm{PNA}_{\text {neg }}$ by almost 15 units, $\mathrm{M}_{\text {pos }} /$ $\mathrm{PI}_{\text {neg }} \mathrm{PNA}_{\text {neg }}$ values also decreased from $94 \%(0 \mathrm{~h})$ to approximately $85 \%(3 \mathrm{~h})$. Indeed, bulls of the 2 fertility groups showed similar response to incubation stress. Based on the 9-unit decrease of $\mathrm{M}_{\text {pos }} / \mathrm{PI}_{\text {neg }} \mathrm{PNA}_{\text {neg }}$, one can support that incubation had an adverse effect not only on the number of $\mathrm{PI}_{\text {neg }} \mathrm{PNA}_{\text {neg }}$ sperm but also on their ability to maintain high MMP, subsequently increasing the heterogeneity of the $\mathrm{PI}_{\text {neg }} \mathrm{PNA}_{\text {neg }}$ sperm sub-population. Though statistically significant, the decrease of $\mathrm{F}_{\text {neg }} / \mathrm{PI}_{\text {neg }} \mathrm{PNA}_{\text {neg }}$ during incubation (by approximately 3 units) was less pronounced than that of $\mathrm{M}_{\text {pos }} / \mathrm{PI}_{\text {neg }} \mathrm{PNA}_{\text {neg. }}$. As reviewed by Kroemer et al. (2007), prolonged mitochondrial dysfunction can be perceived as the first manifestation of cellular death, whereas other signs, like the loss of plasma membrane structural integrity and DNA fragmentation, usually follow. In humans, Kim et al. (2013) detected a subpopulation of apoptotic sperm after 2-h incubation

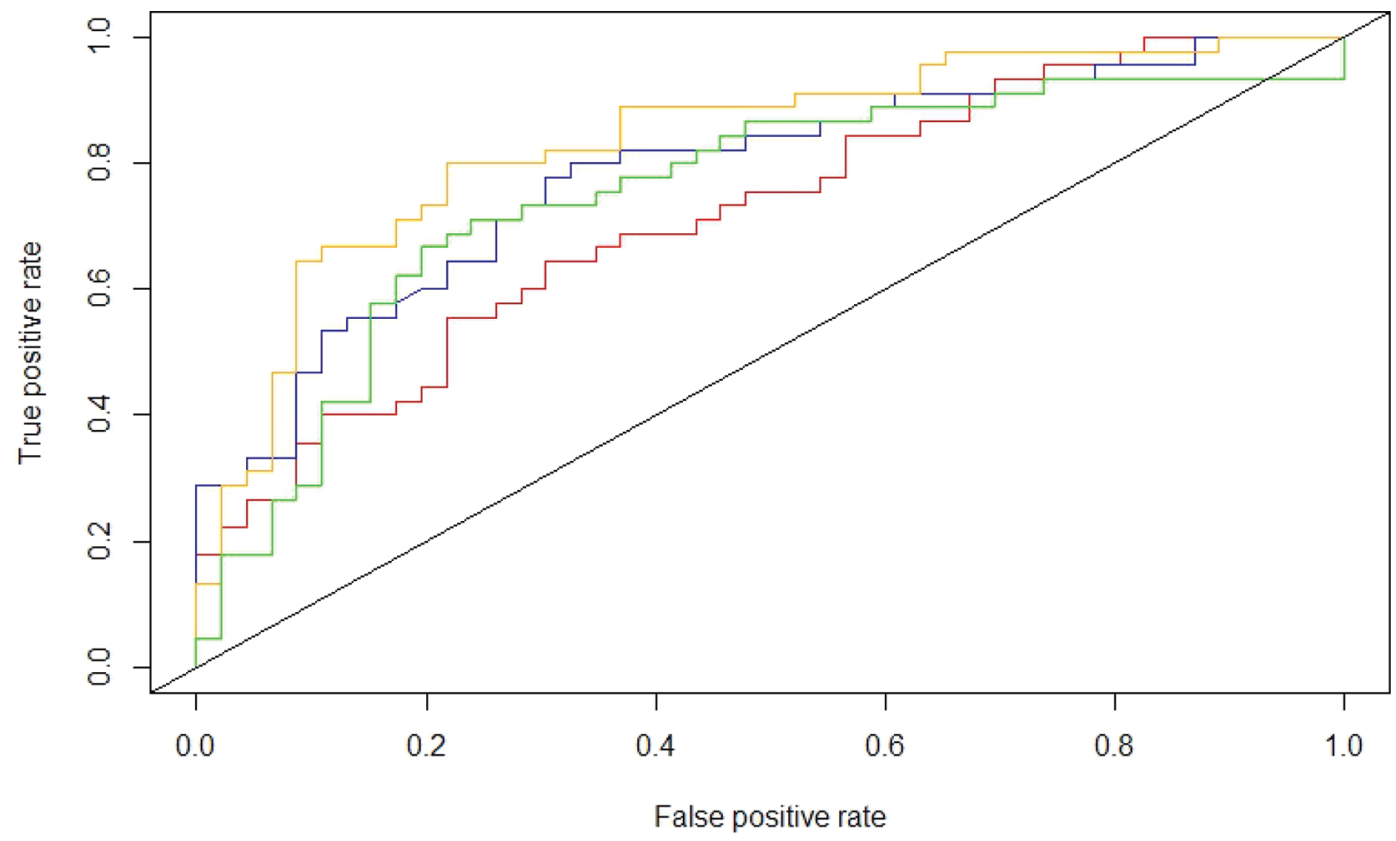

Figure 3. Receiver operating characteristic curves for 4 different combinations of sperm traits used to distinguish the fertility class (high fertility, low fertility) of 91 cryopreserved bovine ejaculates. The random forest algorithm was used for the construction of 4 binary classifiers including (A) 18 sperm traits assessed with a multicolor flow cytometry at $0 \mathrm{~h}$ (red curve), (B) 18 sperm traits assessed with a multicolor flow cytometry at $3 \mathrm{~h}$ (blue curve), (C) $\mathrm{F}_{\text {neg }} / \mathrm{PI}_{\text {neg }} \mathrm{M}_{\text {pos }}$ and \%DFI at $0 \mathrm{~h}$ (orange curve), and (D) $\mathrm{F}_{\text {neg }} / \mathrm{PI}_{\text {neg }} \mathrm{M}_{\text {pos }}$ and rapid motility at $3 \mathrm{~h}$ (green curve). The area under the curve of the above described classifiers was $0.723,0.767,0.857$, and 0.751 , respectively. Variables $\mathrm{F}_{\text {neg }} / \mathrm{PI}_{\text {neg }} \mathrm{M}_{\mathrm{pos}}$ and $\% \mathrm{DFI}$ represent the percentage of sperm with low intracellular $\mathrm{Ca}^{2+}$ levels within the plasma membrane-intact and mitochondria-functional population, and the percentage of sperm with high DNA fragmentation index, respectively. The diagonal black line represents a no-discrimination classifier. 


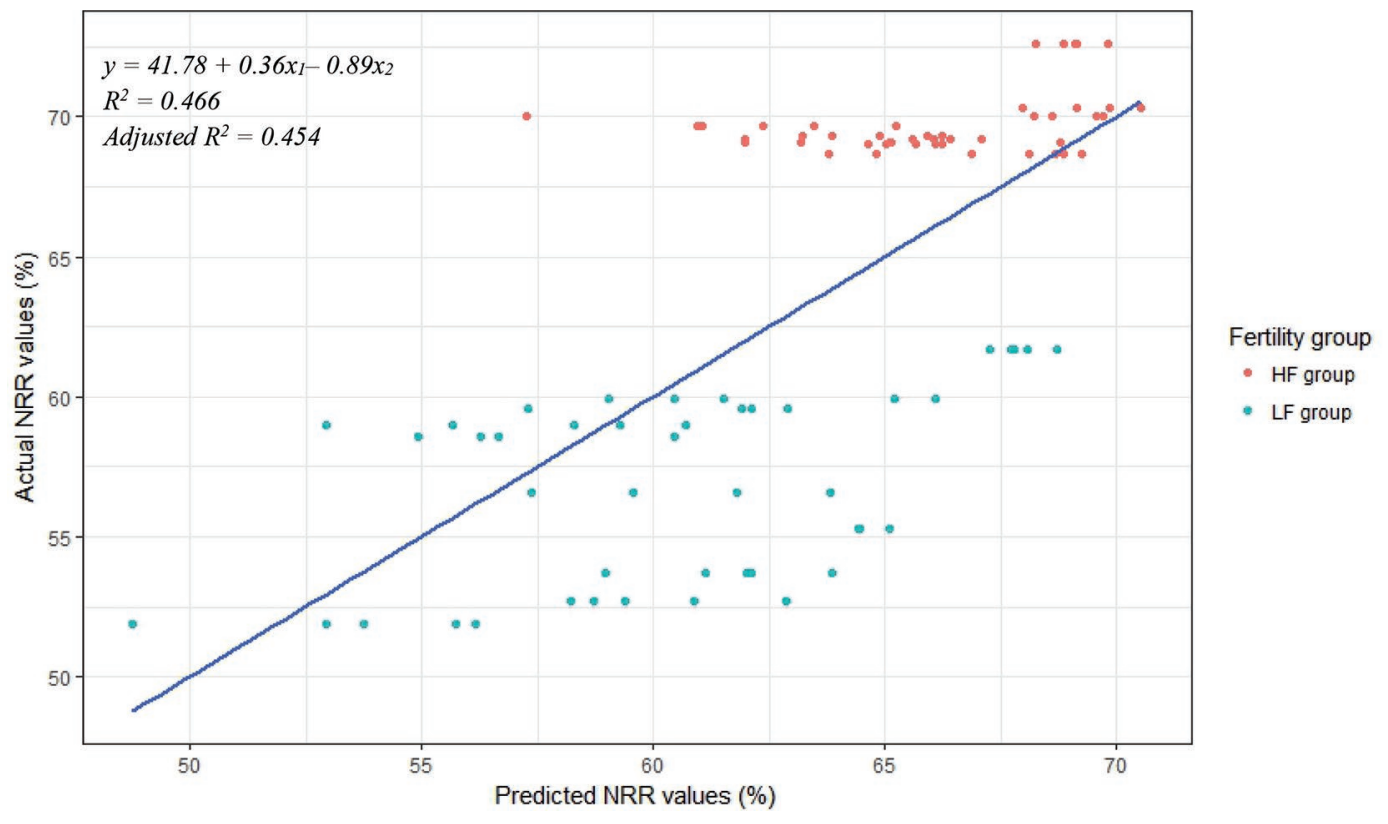

Figure 4. The linear regression line describing the relation between the predicted (x-axis) and the actual (y-axis) values of the annual 56-d non-return rate (NRR) recorded for 10 high- (HF) and 10 low-fertility (LF) Holstein-Friesian bulls. Values of NRR were modeled as function of $\mathrm{F}_{\text {neg }} / \mathrm{PI}_{\text {neg }} \mathrm{M}_{\text {pos }}(\%)$ and \%DFI determined for 4 to 5 cryopreserved ejaculates per bull (91 ejaculates in total) immediately after thawing. Variables $\mathrm{F}_{\text {neg }} / \mathrm{PI}_{\mathrm{neg}} \mathrm{M}_{\mathrm{pos}}$ and \%DFI represent the percentage of sperm with low intracellular $\mathrm{Ca}^{2+}$ levels within the plasma membrane-intact and mitochondria-functional population, and the percentage of sperm with high DNA fragmentation index, respectively.

through the distinct reduction of their $\mathrm{DiIC}_{1}(5)$ signal. Changes of MMP preceded those of plasma membrane structure urging the authors to support the mitochondrial origin of apoptosis in human sperm (Kim et al., 2013). Similar findings have been reported in the bull, where the correlation between sperm plasma membrane integrity and MMP diminishes in power after short-term incubation (Bollwein et al., 2008). Our results showed that the inclusion of $\operatorname{DiIC}_{1}(5)$ in the fluorescent panel was of questionable informative value at $0 \mathrm{~h}$; however, it allowed the detection of incubation-mediated changes in the mitochondrial function of $\mathrm{PI}_{\text {neg }} \mathrm{PNA}_{\text {neg }}$ sperm, which could be interpreted as an early indicator of viability loss in frozen-thawed bovine sperm.

Including Fluo-4 AM in the flow cytometric panel, it became possible to recognize viable cells with low $\left[\mathrm{Ca}^{2+}\right]_{\mathrm{i}}$. It is known that bovine spermatozoa are not capable of fertilizing the oocyte right after ejaculation; they first have to go through a maturation process known as capacitation (Gervasi and Visconti, 2016). The induction and regulation of a series of events typical for sperm in capacitation mode (e.g., removal of surface seminal plasma proteins, alterations of membrane fluidity, hyperactivation, chemotactic motility, and acrosomal exocytosis) require a complex network of signaling pathways. In this frame, spatio-temporal alterations of $\left[\mathrm{Ca}^{2+}\right]_{\mathrm{i}}$ act as the centerpiece of a mechanism that ultimately triggers acrosome reaction
(Breitbart, 2002; Rahman et al., 2014). Cryopreserved mammalian sperm are susceptible to capacitation-like changes partially mediated by an increased $\mathrm{Ca}^{2+}$ efflux shortly after thawing (Thomas et al., 2006; Miah et al., 2011; Almadaly et al., 2015). To avoid the untimely and abrupt rise of their $\left[\mathrm{Ca}^{2+}\right]_{\mathrm{i}}$, bovine spermatozoa show only minimum uptake of $\mathrm{Ca}^{2+}$ after ejaculation, even at increasing extracellular $\left[\mathrm{Ca}^{2+}\right]$ (Rufo et al., 1984). The premature capacitation and induction of acrosome reaction decreases the longevity of frozen-thawed sperm in the female genital tract. Thus, the existence of a sufficient sperm sub-population in cryopreserved semen that can maintain their $\left[\mathrm{Ca}^{2+}\right]_{\mathrm{i}}$ in low levels post-thaw is considered essential for sperm fertilizing ability. Although the adverse effect of cryopreservation on the ability of sperm to regulate $\mathrm{Ca}^{2+}$ efflux has been previously demonstrated in the bull (Bailey and Buhr, 1994) and buffalo (Kadirvel et al., 2009), we are not aware of relevant threshold values routinely used for quality control of cryopreserved semen.

In an attempt to evaluate the relation of bull fertility to the functional status of frozen-thawed sperm, group-dependent differences of the $18 \mathrm{MC}$ traits were explored by means of linear mixed-effects modeling. In overall, MC traits did not differ between $\mathrm{HF}$ and $\mathrm{LF}$ bulls; exceptions to that were the variables $\mathrm{C}_{\mathrm{pos}} \mathrm{F}_{\text {neg }}$, $\mathrm{F}_{\text {neg }} / \mathrm{PI}_{\text {neg }} \mathrm{PNA}_{\text {neg }}$, and $\mathrm{F}_{\text {neg }} / \mathrm{PI}_{\text {neg }} \mathrm{M}_{\text {pos }}$. Our findings were not consistent with previous studies supporting the im- 
portance of sperm viability and mitochondrial activity for the characterization of bull fertility (Tartaglione and Ritta, 2004; Christensen et al., 2005; Sellem et al., 2015), since we failed to detect any group-dependent differences of $\mathrm{PI}_{\text {neg }} \mathrm{C}_{\text {pos }}$ and $\mathrm{PI}_{\text {neg }} \mathrm{M}_{\text {pos }}$ using the linearmodel approach. This could be attributed to the fact that the examined semen batches of both fertility groups had sufficiently high viability to pass the in-house quality control before being released to the market.

Despite the inconsiderable differences of $\mathrm{PI}_{\text {neg }} \mathrm{PNA}_{\text {neg }}$ and $\mathrm{PI}_{\text {neg }} \mathrm{M}_{\text {pos }}$ sperm between the HF and LF bulls, the ability of these sperm to regulate their $\left[\mathrm{Ca}^{2+}\right]_{\mathrm{i}}$ varied in relation to the fertility status of the bull. In particular, the fraction of $\mathrm{F}_{\text {neg }}$ sperm within the $\mathrm{PI}_{\text {neg }} \mathrm{PNA}_{\text {neg }}$ and
$\mathrm{PI}_{\text {neg }} \mathrm{M}_{\text {pos }}$ sub-population $\left(\mathrm{F}_{\text {neg }} / \mathrm{PI}_{\text {neg }} \mathrm{PNA}_{\text {neg }}\right.$ at $0 \mathrm{~h}, \mathrm{~F}_{\text {neg }} /$ $\mathrm{PI}_{\text {neg }} \mathrm{M}_{\text {pos }}$ at 0 and $3 \mathrm{~h}$ ) was higher in HF than in LF bulls. Interestingly, incubation stress decreased the heterogeneity of $\mathrm{PI}_{\text {neg }} \mathrm{PNA}_{\text {neg }}$ sperm regarding their ability to maintain low $\left[\mathrm{Ca}^{2+}\right]_{\mathrm{i}}$, as $\mathrm{F}_{\text {neg }} / \mathrm{PI}_{\text {neg }} \mathrm{PNA}_{\text {neg }}$ values differed between HF and LF bulls at $0 \mathrm{~h}$ but not at $3 \mathrm{~h}$. Remarkably, LF bulls were able to roughly maintain their $\mathrm{F}_{\text {neg }} / \mathrm{PI}_{\text {neg }} \mathrm{PNA}_{\text {neg }}$ values between 0 and $3 \mathrm{~h}$; however, that was not the case for HF bulls that showed a more pronounced decrease of $\mathrm{F}_{\text {neg }} / \mathrm{PI}_{\text {neg }} \mathrm{PNA}_{\text {neg. }}$. Previous research has also suggested a link between the efficient regulation of sperm $\left[\mathrm{Ca}^{2+}\right]_{\mathrm{i}}$ and bull fertility (Collin et al., 2000). Experiments in mice showed that the inhibition of the voltage-dependent anion channel,

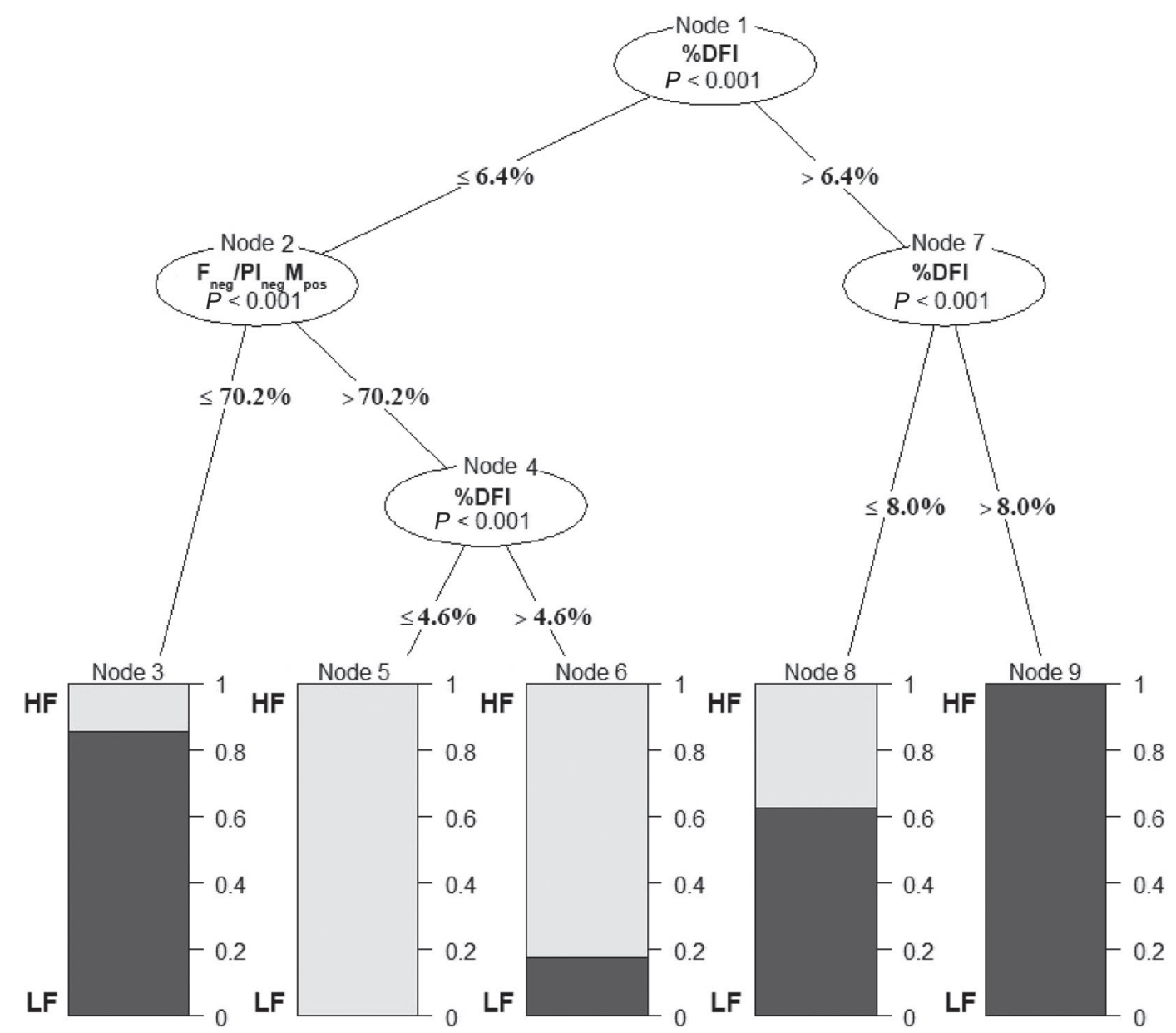

Figure 5. Example of a decision tree built using the random forest ensemble learning method, with 9 branching points (nodes) and 2 sperm traits $\left(\mathrm{F}_{\text {neg }} / \mathrm{PI}_{\text {neg }} \mathrm{M}_{\text {pos }}, \% \mathrm{DFI}\right)$ as predictors of bull fertility status. The percentage of sperm with low intracellular Ca ${ }^{2+}$ levels within the plasma membrane-intact and mitochondria-functional population $\left(\mathrm{F}_{\text {neg }} / \mathrm{PI}_{\text {neg }} \mathrm{M}_{\mathrm{pos}}\right)$ as well as the percentage of sperm with high DNA fragmentation index (\%DFI) were flow cytometrically assessed in 91 cryopreserved ejaculates collected from 10 high- (HF) and 10 low-fertility (LF) HolsteinFriesian bulls, immediately after thawing. The random forest algorithm used different bootstrap samples of the original data to construct a set of decision trees. At each node, one predicting variable (sperm trait) was selected as optimal classifier (the one that resulted in the higher possible reduction of data variance). Along the branch (black line) originating from each decision node (nodes 1, 2, 4, and 7), the cut-off value of the sperm trait that was selected as an optimum predictor is demonstrated. Within each decision node, the predicted class probability $P$ is also presented. Nodes $3,5,6,8$, and 9 are terminal and, thus, no longer split in sub-nodes. At each terminal node, the ratio of ejaculates classified as HF or LF is presented in a cumulative bar (gray-shaded or black area, respectively). 
a protein mediating the transmembrane $\mathrm{Ca}^{2+}$ flux in male gametes, impairs sperm function and decreases cleavage rate of in vitro produced embryos (Kwon et al., 2013). Moreover, knocking out the sperm-specific cation channels, widely known as CatSper, leads to disruption of $\mathrm{Ca}^{2+}$ efflux and infertility in male mice (Ren et al., 2001). Relevant studies in the bull have also suggested that disturbances of $\mathrm{Ca}^{2+}$ homeostasis and efflux regulation adversely affect the ability of sperm to approach the fertilization site and undergo the acrosome reaction (Fraser et al., 1995; Mondal et al., 2017). In the light of this information, it is not surprising that $\mathrm{F}_{\text {neg }} / \mathrm{PI}_{\text {neg }} \mathrm{PNA}_{\text {neg }}$ and $\mathrm{F}_{\text {neg }} / \mathrm{PI}_{\text {neg }} \mathrm{M}_{\text {pos }}$ at $0 \mathrm{~h}$ were the sperm traits to show the strongest correlation to NRR values of the selected bulls. On the other hand, this highlights the value of assessing sperm functional heterogeneity in commercially produced semen, a task feasible by means of multicolor flow cytometry.

One of the main goals of the present study was to evaluate the multicolor flow cytometric analysis of bovine sperm as a tool for bull fertility prognostics. In contrast to the widely used linear regression approach, machine learning algorithms, like RF, offer several features that could be relevant to the analysis of data sets obtained through laboratory semen analysis. The RF classifiers are able to capture both linear and nonlinear relations between the predictors and the outcome variable, whereas they can adequately cope with missing values and overlapping information coming from intercorrelated predictors (Boulesteix et al., 2012), phenomena commonly observed in sperm analysis data sets (Utt, 2016). Though widely used in other biomedical fields, especially for the identification and evaluation of disease-relevant molecular markers (Touw et al., 2013), RF-based prediction schemes are only scarce in animal reproductive medicine. Recently, independent studies conducted in Ireland and the United States reported the employment of RF for the prediction of the conception rate in artificially inseminated dairy cows based on milk infrared spectrum data, and female- and herdspecific factors (Shahinfar et al., 2014; Hempstalk et al., 2015; Fenlon et al., 2016). Despite the increasing availability of advanced data analysis tools, the relation between sperm quality characteristics and the outcome of artificial insemination has traditionally been treated as a linear one and explored by means of regression analysis (Phillips et al., 2004; Tartaglione and Ritta, 2004; Gillan et al., 2008; Oliveira et al., 2013; Sellem et al., 2015; Gliozzi et al., 2017; Kumaresan et al., 2017). Furthermore, the predictive models described up to now require the combination of more than one or not usually within-reach laboratory methods to obtain the necessary input data set, which makes them less attractive for routine application.
According to our results, the examination of cryopreserved semen through a single analytical procedure (i.e., the 5-color flow cytometric assay) appeared to be adequate for the accurate characterization of bull fertility. The predictability of the fertility status was further improved after subjecting sperm to a 3-h incubation stress, with the OOB error rate decreasing from 34.07 to $30.77 \%$ between 0 and $3 \mathrm{~h}$. Based on current knowledge, bull fertility can be only partially predicted even by elaborate combinations of sperm quality characteristics; researchers have been able to explain a variable part (between 40 and $83 \%$ ) of the variation of the conception rate or NRR of a sire (Phillips et al., 2004; Tartaglione and Ritta, 2004; Sellem et al., 2015; Gliozzi et al., 2017; Kumaresan et al., 2017), but a considerable fraction of it still remains unexplained.

Interestingly, the performance of the $\mathrm{RF}$ fertility classifier was not equal among ejaculates of different fertility groups. In particular, a 3-unit difference in the classification error rate of the HF and LF samples was observed (32.61 and $35.55 \%$ classification error rate at $0 \mathrm{~h}$, respectively), but this difference was more prominent after $3 \mathrm{~h}$ of incubation. This observation implies that the set of sperm traits used as input for the RF algorithm was not equally efficient for the identification of LF compared with HF bulls. Recently, Kumaresan et al. (2017) performed principal component analysis to detect the sperm qualities that most adequately characterize the fertilizing potential of Holstein sires. The authors demonstrated that different aspects of sperm function were critical for samples obtained from bulls of different fertility. In particular, the size of the membrane- and acrosome-intact sperm population as well as the oxidative status of sperm were important for the characterization of high-fertility ejaculates. On the contrary, samples of lower fertility were mainly identified through the increased fraction of dead sperm and higher \%DFI values (Kumaresan et al., 2017). Another probable explanation for the group-dependent efficiency of the applied RF algorithm could be the different variability of the 2 fertility groups examined in the present study. Whereas NRR values of the HF bulls were closely dispersed around the group mean $(69.66 \pm$ $1.12 \%$ ), the distribution of NRR values showed a 3 -fold higher standard deviation in the LF group (56.90 \pm $3.34 \%$ ); not surprisingly, the less well defined the target population, the lower the accuracy of the prediction algorithm.

The analysis of the $18 \mathrm{MC}$ traits highlighted $\mathrm{F}_{\text {neg }} /$ $\mathrm{PI}_{\text {neg }} \mathrm{M}_{\text {pos }}$ sperm as the most important feature for the characterization of bull fertility. Based on the values of the variable importance measures, MDA and MDGI, $\mathrm{F}_{\text {neg }} / \mathrm{PI}_{\text {neg }} \mathrm{M}_{\text {pos }}$ outperformed all other MC traits at both incubation time points, meanwhile showing the highest 
correlation to NRR values in comparison to all other $\mathrm{MC}$, SCSA, and CASA traits at $0 \mathrm{~h}$. Our findings are consistent with a previous study of Collin et al. (2000), who demonstrated a significant correlation between the adjusted NRR values of AI bulls and the $\left[\mathrm{Ca}^{2+}\right]_{\mathrm{i}}$ of flow cytometrically assessed sperm loaded with the Indo-1 calcium indicator. The authors reported significant differences in the $\left[\mathrm{Ca}^{2+}\right]_{\mathrm{i}}$ of cryopreserved sperm obtained from high- and low-fertility bulls immediately after thawing (35 and $59 \mathrm{n} M$, respectively) as well as after a 4-h incubation (148 and $206 \mathrm{n} M$, respectively); this observation urged the authors to suggest $\left[\mathrm{Ca}^{2+}\right]_{i}$ already at $0 \mathrm{~h}$ as a sufficient discriminator between sires of different fertility status (Collin et al., 2000).

Independent studies have highlighted the role of sperm mitochondria in the regulation of $\left[\mathrm{Ca}^{2+}\right]_{\mathrm{i}}$. Functional mitochondria not only accumulate a large fraction of $\mathrm{Ca}^{2+}$ uptake (up to $64 \%$ of ATP-dependent $\mathrm{Ca}^{2+}$ uptake; Dragileva et al., 1999), but also play an important role in the regulation of $\mathrm{Ca}^{2+}$ entry through store-operated calcium channels (Ardón et al., 2009). As shown by Ardón et al. (2009), the inhibition of mitochondrial function leads to a depletion of intracellular mitochondrial $\mathrm{Ca}^{2+}$ stores, subsequently resulting in an increased $\mathrm{Ca}^{2+}$ influx through store-operated calcium channels. Given this information, we could assume that the combined ability of viable sperm to regulate their $\left[\mathrm{Ca}^{2+}\right]_{\mathrm{i}}$ and maintain functional mitochondria, as reflected by $\mathrm{F}_{\text {neg }} / \mathrm{PI}_{\text {neg }} \mathrm{M}_{\text {pos }}$ values in the present study, is critical for the characterization of bull fertility.

The predictability of bull fertility status was further improved when multicolor flow cytometry was combined with the SCSA. In particular, the OOB error rate of the prediction algorithm decreased from 34.07 to $24.18 \%$ when combining $\mathrm{F}_{\text {neg }} / \mathrm{PI}_{\text {neg }} \mathrm{M}_{\text {pos }}$ with \%DFI at $0 \mathrm{~h}$. In the same time, almost $50 \%$ of the total NRR variation could be explained through a linear combination of $\mathrm{F}_{\text {neg }} / \mathrm{PI}_{\text {neg }} \mathrm{M}_{\text {pos }}$ and \%DFI $(0 \mathrm{~h})$. The link of sperm chromatin integrity to bull fertility has been a matter of extended research in the last 2 decades (Evenson, 2016). Deficiencies of chromatin structural integrity are considered noncompensable components of sperm dysfunction, which, therefore, cannot be circumvented by increasing the dose of sperm used for AI (Saacke et al., 2000). Numerous studies employing the SCSA have revealed a relation of variable strength between the percentage of sperm with high DFI and the fertility index of AI sires (Puglisi et al., 2012; Nagy et al., 2013; Sellem et al., 2015; Gliozzi et al., 2017; Morrell et al., 2017). Karoui et al. (2012) highlighted the negative predictive value of sperm DNA fragmentation measures; the authors supported that screening the total bull population in semen production centers for sperm DNA integrity can be efficient for the identification of low-fertility bulls.

It is believed that DNA damage of posttesticular origin does not affect the ability of sperm to fertilize the oocyte; however, it has a detrimental effect on embryonic quality. Independent experiments in the bovine have shown that experimentally induced DNA damage of paternal gametes leads to increased apoptotic rate of embryonic cells after the first cleavages and jeopardizes embryo survival (Fatehi et al., 2006; Simões et al., 2013). Combined with the poor correlation between DNA damage and other in vitro assessed sperm functional traits (Bollwein et al., 2008; Gillan et al., 2008), measures of sperm DNA integrity are believed to provide information about the paternal component in the production of a viable embryo not attainable through other sperm tests. In accordance to the above discussed literature, we were able to confirm the informative value of sperm DFI, as the predictability of bull fertility was further improved by the addition of \%DFI in the prediction algorithm.

After numerous repetitions of the RF classifier using $\mathrm{F}_{\text {neg }} / \mathrm{PI}_{\text {neg }} \mathrm{M}_{\text {pos }}$ and \%DFI $(0 \mathrm{~h})$ as predictors of the 2 fertility groups, certain patterns were recognized. It appeared that bulls with \%DFI higher than $8 \%$ (regardless of their $\mathrm{F}_{\text {neg }} / \mathrm{PI}_{\text {neg }} \mathrm{M}_{\text {pos }}$ values) were consistently classified as LF; that was also the case for bulls with $\mathrm{F}_{\text {neg }} / \mathrm{PI}_{\text {neg }} \mathrm{M}_{\text {pos }}$ values lower than $70 \%$. Although previous reports on the minimum percentage of sperm with low $\left[\mathrm{Ca}^{2+}\right]_{\mathrm{i}}$ are not available, we are aware of studies suggesting fertility-relevant threshold values for \%DFI either similar to (Karoui et al., 2012; Puglisi et al., 2012) or higher than ours (Januskauska et al., 2001, 2003).

In the present study, one can easily recognize certain limitations that necessitate the validation of our results with larger and more heterogeneous data sets before being able to establish an efficient predicting scheme and specific cut-off values for sperm functional traits. The biological material and fertility data used in the present study originated from 20 bulls of uniform breed (Holstein-Friesian) housed in a single semen production center. As recently shown by Morrell et al. (2017), the relation of bull fertility to sperm quality can be breed-dependent, which implies that the contribution of certain sperm features to fertility prognostics can vary between bulls of different breed. Furthermore, several station-related factors (e.g., bull selection strategy, standards applied at semen quality control, distribution of batches in the market, collection of fertility data) apparently had an effect on the quality of samples made available for the experimental part of our study as well as on the fertility data used for the selection of bulls and 
the statistical analysis of our data set. Consequently, one cannot overlook the necessity of a follow-up largerscale study that would focus on the validation of the present findings and potentially the establishment of cut-off values for sperm functional parameters assessed through the described multicolor assay.

\section{CONCLUSIONS}

In the present study, 5 fluorescent probes were combined in a single flow cytometric assay to simultaneously assess the viability, acrosomal status, intracellular calcium levels, and mitochondrial function of cryopreserved bovine sperm obtained from low- and high-fertility sires. A set of 18 traits reflecting different aspects of sperm functionality was determined through the applied assay. The analysis of the data revealed the functional heterogeneity of the parent sperm population as well as of sub-ordinary sperm groups within each semen sample. Alterations of sperm functional status were further highlighted by subjecting sperm to a shortterm incubation at $38^{\circ} \mathrm{C}$. Our results suggested that the vast majority of plasma membrane-intact sperm with unstained acrosome carried functional mitochondria at $0 \mathrm{~h}$; however, the ability of these cells to maintain an active MMP was considerably impaired by incubation stress. Though less pronounced, incubation-mediated alterations of intracellular calcium levels in $\mathrm{PI}_{\text {neg }} \mathrm{PNA}_{\text {neg }}$ sperm were also observed. Using the data obtained through a single sperm examination, the 5-color flow cytometric assay, it was possible to accurately classify two-thirds of the examined ejaculates in 1 of the 2 fertility groups. The fraction of sperm that maintained low $\left[\mathrm{Ca}^{2+}\right]_{\mathrm{i}}$ within the $\mathrm{PI}_{\text {neg }} \mathrm{M}_{\text {pos }}$ sub-population appeared to be the most determining predictor of bull fertility. To our knowledge, this is the first time that a 5-color fluorescent panel is described for the flow cytometric analysis of commercially produced bovine semen. Our findings revealed part of the functional heterogeneity of cryopreserved sperm, otherwise not detectable through 1- or 2-color assays. More importantly, the multi-parametric characterization of sperm functionality through flow cytometry enabled the prediction of bull fertilizing ability.

\section{ACKNOWLEDGMENTS}

The authors acknowledge the support of Erwin Hasenpusch, Rinderzucht Schleswig-Holstein eG, Neumünster, Germany, and Ulrich Witschi, Swissgenetics, Zollikofen, Switzerland.

\section{REFERENCES}

Almadaly, E., Y. Hoshino, T. Ueta, K. Mukoujima, M. Shukry, F. Farrag, I. El-Kon, K. Kita, and T. Murase. 2015. Desalted and lyophilized bovine seminal plasma delays induction of the acrosome reaction in frozen-thawed bovine spermatozoa in response to calcium ionophore. Theriogenology 83:175-185. https://doi.org/10 .1016/j.theriogenology.2014.09.004.

Amann, R. P., and J. M. DeJarnette. 2012. Impact of genomic selection of AI dairy sires on their likely utilization and methods to estimate fertility: A paradigm shift. Theriogenology 77:795-817. https://doi.org/10.1016/j.theriogenology.2011.09.002.

Amann, R. P., and R. H. Hammerstedt. 1993. In vitro evaluation of sperm quality: An opinion. J. Androl. 14:397-406.

Amaral, A., B. Lourenco, M. Marques, and J. Ramalho-Santos. 2013. Mitochondria functionality and sperm quality. Reproduction 146. https://doi.org/10.1530/REP-13-0178.

Ardón, F., E. Rodríguez-Miranda, C. Beltrán, A. Hernández-Cruz, and A. Darszon. 2009. Mitochondrial inhibitors activate influx of external $\mathrm{Ca}^{2+}$ in sea urchin sperm. Biochim. Biophys. Acta 1787:15-24. https://doi.org/10.1016/j.bbabio.2008.10.003.

Bailey, J. L., and M. M. Buhr. 1994. Cryopreservation alters the $\mathrm{Ca}^{2+}$ flux of bovine spermatozoa. Can. J. Anim. Sci. 74:45-51.

Barroso, G., S. Taylor, M. Morshedi, F. Manzur, F. Gaviño, and S. Oehninger. 2006. Mitochondrial membrane potential integrity and plasma membrane translocation of phosphatidylserine as early apoptotic markers: A comparison of two different sperm subpopulations. Fertil. Steril. 85:149-154. https://doi.org/10.1016/j .fertnstert.2005.06.046.

Birck, A., P. Christensen, R. Labouriau, J. Pedersen, and S. Borchersen. 2010. In vitro induction of the acrosome reaction in bull sperm and the relationship to field fertility using low-dose inseminations. Theriogenology 73:1180-1191. https://doi.org/10.1016/j .theriogenology.2009.10.010.

Bollwein, H., I. Fuchs, and C. Koess. 2008. Interrelationship between plasma membrane integrity, mitochondrial membrane potential and DNA fragmentation in cryopreserved bovine spermatozoa. Reprod. Domest. Anim. 43:189-195. https://doi.org/10.1111/j.1439 $-0531.2007 .00876 . x$

Boulesteix, A. L., S. Janitza, J. Kruppa, and I. R. König. 2012. Overview of random forest methodology and practical guidance with emphasis on computational biology and bioinformatics. Wiley Interdiscip. Rev. Data Min. Knowl. Discov. 2:493-507. https://doi .org/10.1002/widm.1072.

Breiman, L. 2001. Random forests. Mach. Learn. 45:5-32. https://doi . org/10.1023/A:1010933404324.

Breitbart, H. 2002. Intracellular calcium regulation in sperm capacitation and acrosomal reaction. Mol. Cell. Endocrinol. 187:139-144. https://doi.org/10.1016/S0303-7207(01)00704-3.

Bucher, K., E. Malama, M. Siuda, U. Witschi, E. Hasenpusch, T. Röpke, F. Janett, and H. Bollwein. 2017. Use of a multi- color flow cytometric assay for the evaluation of bull fertility. Page 75 in Reprod. Domest. Anim. 52(S3) Proceedings of the 21st Annual Conference of the European Society for Domestic Animal Reproduction (ESDAR), Bern, Switzerland. https://doi.org/10.1111/ rda.13026.

Christensen, P., D. Boelling, K. M. Pedersen, I. R. Korsgaard, and J. Jensen. 2005. Relationship between sperm viability as determined by flow cytometry and nonreturn rate of dairy bulls. J. Androl. 26:98-106.

Christensen, P., R. Labouriau, A. Birck, G. B. Boe-Hansen, J. Pedersen, and S. Borchersen. 2011. Relationship among seminal quality measures and field fertility of young dairy bulls using low-dose inseminations. J. Dairy Sci. 94:1744-1754. https://doi.org/10.3168/ jds.2010-3087.

Collin, S., M. A. Sirard, M. Dufour, and J. L. Bailey. 2000. Sperm calcium levels and chlortetracycline fluorescence patterns are related to the in vivo fertility of cryopreserved bovine semen. J. Androl. 21:938-943. 
Dragileva, E., S. Rubinstein, and H. Breitbart. 1999. Intracellular $\mathrm{Ca}^{2+}-\mathrm{Mg}^{2+}$-ATPase regulates calcium influx and acrosomal exocytosis in bull and ram spermatozoa. Biol. Reprod. 61:1226-1234.

Evenson, D., and L. Jost. 2001. Sperm chromatin structure assay for fertility assessment. Current Protocols in Cytometry 13:7.13.17.13.27. John Wiley \& Sons Inc. https://doi.org/10.1002/ 0471142956.cy0713s13.

Evenson, D. P. 2016. The Sperm Chromatin Structure Assay (SCSA) and other sperm DNA fragmentation tests for evaluation of sperm nuclear DNA integrity as related to fertility. Anim. Reprod. Sci. 169. https://doi.org/10.1016/j.anireprosci.2016.01.017.

Fatehi, A. N., M. M. Bevers, E. Schoevers, B. A. J. Roelen, B. Colenbrander, and B. M. Gadella. 2006. DNA damage in bovine sperm does not block fertilization and early embryonic development but induces apoptosis after the first cleavages. J. Androl. 27:176-188. https://doi.org/10.2164/jandrol.04152.

Fenlon, C., L. O'Grady, J. Dunnion, L. Shalloo, S. Butler, and M. Doherty. 2016. A comparison of machine learning techniques for predicting insemination outcome in Irish dairy cows. Pages 57-67 in CEUR Workshop Proceedings, Dublin, Ireland.

Ferramosca, A., S. P. Provenzano, L. Coppola, and V. Zara. 2012. Mitochondrial respiratory efficiency is positively correlated with human sperm motility. Urology 79:809-814. https://doi.org/10.1016/ j.urology.2011.12.042.

Fraser, L. R., L. R. Abeydeera, and K. Niwa. 1995. Ca ${ }^{2+}$-Regulating mechanisms that modulate bull sperm capacitation and acrosomal exocytosis as determined by chlortetracycline analysis. Mol. Reprod. Dev. 40:233-241. https://doi.org/10.1002/mrd.1080400213.

Gervasi, M. G., and P. E. Visconti. 2016. Chang's meaning of capacitation: A molecular perspective. Mol. Reprod. Dev. 83:860-874 https://doi.org/10.1002/mrd.22663.

Gillan, L., T. Kroetsch, W. M. C. Maxwell, and G. Evans. 2008. Assessment of in vitro sperm characteristics in relation to fertility in dairy bulls. Anim. Reprod. Sci. 103:201-214. https://doi.org/10 .1016/j.anireprosci.2006.12.010.

Gliozzi, T. M., F. Turri, S. Manes, C. Cassinelli, and F. Pizzi. 2017. The combination of kinetic and flow cytometric semen parameters as a tool to predict fertility in cryopreserved bull semen. Animal 11:1975-1982. https://doi.org/10.1017/S1751731117000684

Hallap, T., S. Nagy, U. Jaakma, A. Johannisson, and H. RodriguezMartinez. 2006. Usefulness of a triple fluorochrome combination Merocyanine 540/Yo-Pro 1/Hoechst 33342 in assessing membrane stability of viable frozen-thawed spermatozoa from Estonian Holstein AI bulls. Theriogenology 65:1122-1136. https://doi.org/10 .1016/j.theriogenology.2005.07.009.

Hempstalk, K., S. McParland, and D. P. Berry. 2015. Machine learning algorithms for the prediction of conception success to a given insemination in lactating dairy cows. J. Dairy Sci. 98:5262-5273. https://doi.org/10.3168/jds.2014-8984.

Hendricks, K. E. M., and P. J. Hansen. 2009. Can programmed cell death be induced in post-ejaculatory bull and stallion spermatozoa? Theriogenology 71:1138-1146. https://doi.org/10.1016/j .theriogenology.2008.12.006.

Januskauska, A., A. Johannisson, and H. Rodriguez-Martinez. 2001. Assessment of sperm quality through fluorometry and sperm chromatin structure assay in relation to field fertility of frozen-thawed semen from Swedish AI bulls. Theriogenology 55:947-961. https:/ /doi.org/10.1016/S0093-691X(01)00456-3.

Januskauska, A., A. Johannisson, and H. Rodriguez-Martinez. 2003. Subtle membrane changes in cryopreserved bull semen in relation with sperm viability, chromatin structure, and field fertility. Theriogenology 60:743-758. https://doi.org/10.1016/S0093 $-691 X(03) 00050-5$.

Kadirvel, G., S. Kumar, A. Kumaresan, and P. Kathiravan. 2009. Capacitation status of fresh and frozen-thawed buffalo spermatozoa in relation to cholesterol level, membrane fluidity and intracellular calcium. Anim. Reprod. Sci. 116:244-253. https://doi.org/10 .1016/j.anireprosci.2009.02.003.

Kanno, C., S.-S. Kang, Y. Kitade, Y. Yanagawa, Y. Takahashi, and M. Nagano. 2016. Simultaneous evaluation of plasma membrane integrity, acrosomal integrity, and mitochondrial membrane poten- tial in bovine spermatozoa by flow cytometry. Zygote 24:529-536 https://doi.org/10.1017/S0967199415000490.

Karoui, S., C. Díaz, M. E. Amenabar, M. Serrano, E. Ugarte, J. Gosálvez, R. Roy, C. López-Fernández, and M. J. Carabaño. 2012. Is sperm DNA fragmentation a good marker for field AI bull fertility? J. Anim. Sci. 90:2437-2449. https://doi.org/10.2527/jas.2011 $-4492$.

Kim, H. H., M. Funaro, S. Mazel, M. Goldstein, P. N. Schlegel, and D. A. Paduch. 2013. Flow cytometric characterization of apoptosis and chromatin damage in spermatozoa. Reprod. Biomed. Online 26:393-395. https://doi.org/10.1016/j.rbmo.2012.12.005.

Kroemer, G., L. Galluzzi, and C. Brenner. 2007. Mitochondrial membrane permeabilization in cell death. Physiol. Rev. 87:99-163. https://doi.org/10.1152/physrev.00013.2006.

Kumaresan, A., A. Johannisson, E. M. Al-Essawe, and J. M. Morrell. 2017. Sperm viability, reactive oxygen species, and DNA fragmentation index combined can discriminate between above- and below-average fertility bulls. J. Dairy Sci. 100:5824-5836. https:// doi.org/10.3168/jds.2016-12484.

Kwon, W. S., Y. J. Park, E. S. A. Mohamed, and M. G. Pang. 2013 Voltage-dependent anion channels are a key factor of male fertility. Fertil. Steril. 99:354-361. https://doi.org/10.1016/j.fertnstert .2012.09.021.

Lee, J. A., J. Spidlen, K. Boyce, J. Cai, N. Crosbie, J. Furlong, M. Gasparetto, M. Goldberg, E. Goralczyk, B. Hyun, K. Jansen, T. Kollmann, M. Kong, R. Leif, T. Moloshok, W. Moore, G. Nolan, J. Nolan, D. Parrish, B. Purcell, Y. Qian, B. Selvaraj, C. Smith, O. Tchuvatkina, A. Wertheimer, and P. Wilkinson. 2008. MIFlowCyt: The minimum information about a flow cytometry experiment. Cytometry A 73:926-930. https://doi.org/10.1002/cyto.a.20623.

Liaw, A., and M. Wiener. 2002. Classification and regression by random forest. R News 2:18-22.

Malama, E., F. Janett, M. Siuda, K. Wanek, U. Witschi, and H. Bollwein. 2016. Predictability of fertility in Brown Swiss bulls using computer-assisted motility analysis and flow cytometric assays to determine quality of frozen thawed sperm. 49th Annual Conference of Physiology and Pathology of Reproduction, 41st Joint Conference on Veterinary and Human Reproductive Medicine. European Society for Domestic Animal Reproduction (ESDAR), Leipzig, Germany.

Meier, A. 2017. Risk factor study of pododermatitis in rabbits using additive Bayesian networks. Master Thesis in Biostatistics (STA495). Section of Epidemiology, University of Zurich, Zurich, Switzerland

Miah, A. G., U. Salma, P. B. Sinha, M. Hölker, D. Tesfaye, M. U. Cinar, H. Tsujii, and K. Schellander. 2011. Intracellular signaling cascades induced by relaxin in the stimulation of capacitation and acrosome reaction in fresh and frozen-thawed bovine spermatozoa. Anim. Reprod. Sci. 125:30-41. https://doi.org/10.1016/ j.anireprosci.2011.03.010.

Mondal, M. A., Y. Takagi, S. A. Baba, and K. Hamano. 2017. Involvement of calcium channels and intracellular calcium in bul sperm thermotaxis. J. Reprod. Dev. 63:143-148. https://doi.org/ 10.1262/jrd.2016-107.

Morrell, J. M., T. Nongbua, S. Valeanu, I. Lima Verde, K. LundstedtEnkel, A. Edman, and A. Johannisson. 2017. Sperm quality variables as indicators of bull fertility may be breed dependent. Anim. Reprod. Sci. 185:42-52. https://doi.org/10.1016/j.anireprosci.2017 .08 .001 .

Nagy, S., T. Hallap, A. Johannisson, and H. Rodriguez-Martinez. 2004. Changes in plasma membrane and acrosome integrity of frozenthawed bovine spermatozoa during a $4 \mathrm{~h}$ incubation as measured by multicolor flow cytometry. Anim. Reprod. Sci. 80:225-235. https://doi.org/10.1016/j.anireprosci.2003.08.003.

Nagy, S., J. Jansen, E. K. Topper, and B. M. Gadella. 2003. A triplestain flow cytometric method to assess plasma- and acrosomemembrane integrity of cryopreserved bovine sperm immediately after thawing in presence of egg-yolk particles. Biol. Reprod. 68:1828-1835. https://doi.org/10.1095/biolreprod.102.011445.

Nagy, S., A. Johannisson, T. Wahlsten, R. Ijäs, M. Andersson, and H. Rodriguez-Martinez. 2013. Sperm chromatin structure and sperm 
morphology: Their association with fertility in AI dairy Ayrshire sires. Theriogenology 79:1153-1161. https://doi.org/10.1016/j .theriogenology.2013.02.011.

Oliveira, L. Z., R. P. de Arruda, A. F. C. de Andrade, E. C. C. Celeghini, P. D. Reeb, J. P. N. Martins, R. M. dos Santos, M. E. Beletti, R. F. G. Peres, F. M. Monteiro, and V. F. M. Hossepian de Lima. 2013. Assessment of in vitro sperm characteristics and their importance in the prediction of conception rate in a bovine timed AI program. Anim. Reprod. Sci. 137:145-155. https://doi.org/10 .1016/j.anireprosci.2013.01.010.

Paoli, D., M. Gallo, F. Rizzo, E. Baldi, S. Francavilla, A. Lenzi, F. Lombardo, and L. Gandini. 2011. Mitochondrial membrane potential profile and its correlation with increasing sperm motility. Fertil. Steril. 95:2315-2319. https://doi.org/10.1016/j.fertnstert .2011.03.059

Petrunkina, A. M., and R. Harrison. 2013. Fluorescence technologies for evaluating male gamete (dys)function. Reprod. Domest. Anim. 48:11-24. https://doi.org/10.1111/rda.12202.

Petrunkina, A. M., and R. A. P. Harrison. 2011. Cytometric solutions in veterinary andrology: Developments, advantages, and limitations. Cytom. Part A 79 A:338-348. https://doi.org/10.1002/cyto .a.21044.

Phillips, N. J., M. R. Mcgowan, S. D. Johnston, and D. G. Mayer. 2004. Relationship between thirty post-thaw spermatozoal characteristics and the field fertility of 11 high-use Australian dairy AI sires. Anim. Reprod. Sci. 81:47-61. https://doi.org/10.1016/S0378 $-4320(03) 00137-4$

Pinheiro, J., D. Bates, S. DebRoy, D. Sarkar, and The R Development Core Team. 2017. nlme: Linear and nonlinear mixed effects models. R Package Version 3.1-131. Accessed Jun. 14, 2017. https:// CRAN.R-project.org/package $=$ nlme.

Puglisi, R., A. Pozzi, L. Foglio, M. Spanò, P. Eleuteri, M. G. Grollino, G. Bongioni, and A. Galli. 2012. The usefulness of combining traditional sperm assessments with in vitro heterospermic insemination to identify bulls of low fertility as estimated in vivo. Anim. Reprod. Sci. 132:17-28. https://doi.org/10.1016/j.anireprosci.2012 .04 .006 .

Rahman, M. S., W. S. Kwon, and M. G. Pang. 2014. Calcium influx and male fertility in the context of the sperm proteome: An update. BioMed Res. Int. 2014. https://doi.org/10.1155/2014/ 841615.

Ren, D., B. Navarro, G. Perez, A. C. Jackson, S. Hsu, Q. Shi, J. L. Tilly, and D. E. Clapham. 2001. A sperm ion channel required for sperm motility and male fertility. Nature 413:603-609. https://doi .org $/ 10.1038 / 35098027$.

Rufo, G. A. Jr., P. Schoff, and H. Lardy. 1984. Regulation of calcium transport in bovine spermatozoa. J. Biol. Chem. 259:2547-2552.

Saacke, R. G., J. Dalton, S. Nadir, R. Nebel, and J. Bame. 2000. Relationship of seminal traits and insemination time to fertilization rate and embryo quality. Anim. Reprod. Sci. 60-61:663-677. https: //doi.org/10.1016/S0378-4320(00)00137-8.

Sellem, E., M. L. W. J. Broekhuijse, L. Chevrier, S. Camugli, E. Schmitt, L. Schibler, and E. P. C. Koenen. 2015. Use of combinations of in vitro quality assessments to predict fertility of bovine semen. Theriogenology 84:1447-1454. https://doi.org/10.1016/j theriogenology.2015.07.035

Shahinfar, S., D. Page, J. Guenther, V. Cabrera, P. Fricke, and K. Weigel. 2014. Prediction of insemination outcomes in Holstein dairy cattle using alternative machine learning algorithms. J. Dairy Sci. 97:731-742. https://doi.org/10.3168/jds.2013-6693.

Simões, R., W. B. Feitosa, A. F. P. Siqueira, M. Nichi, F. F. PaulaLopes, M. G. Marques, M. A. Peres, V. H. Barnabe, J. A. Visintin, and M. E. O. Assumpçaõ. 2013. Influence of bovine sperm DNA fragmentation and oxidative stress on early embryo in vitro development outcome. Reproduction 146:433-441. https://doi.org/ 10.1530/REP-13-0123.

Sing, T., O. Sander, N. Beerenwinkel, and T. Lengauer. 2005. ROCR Visualizing classifier performance in R. Bioinformatics 21:39403941. https://doi.org/10.1093/bioinformatics/bti623.

Tartaglione, C. M., and M. N. Ritta. 2004. Prognostic value of spermatological parameters as predictors of in vitro fertility of frozenthawed bull semen. Theriogenology 62:1245-1252. https://doi.org/ 10.1016/j.theriogenology.2004.01.012.

The R Development Core Team. 2016. A language and environment for statistical computing. R Foundation for Statistical Computing, Vienna, Austria. Accessed Jun. 14, 2017. https://www.R-project .org/.

Thomas, A. D., S. A. Meyers, and B. A. Ball. 2006. Capacitation-like changes in equine spermatozoa following cryopreservation. Theriogenology 65:1531-1550. https://doi.org/10.1016/j.theriogenology 2005.08.022.

Touw, W. G., J. R. Bayjanov, L. Overmars, L. Backus, J. Boekhorst, M. Wels, and A. F. T. Sacha van Hijum. 2013. Data mining in the life sciences with random forest: A walk in the park or lost in the jungle? Brief. Bioinform. 14:315-326. https://doi.org/10.1093/ $\mathrm{bib} / \mathrm{bbs} 034$

Utt, M. D. 2016. Prediction of bull fertility. Anim. Reprod. Sci 169:37-44. https://doi.org/10.1016/j.anireprosci.2015.12.011.

Vincent, P., S. L. Underwood, C. Dolbec, N. Bouchard, T. Kroetsch, and P. Blondin. 2012. Bovine semen quality control in artificial insemination centers. Anim. Reprod. 9:153-165. https://doi.org/ 10.1002/9781118833971.ch74.

Zorova, L. D., V. A. Popkov, E. Y. Plotnikov, D. N. Silachev, I. B. Pevzner, S. S. Jankauskas, V. A. Babenko, S. D. Zorov, A. V. Balakireva, M. Juhaszova, S. J. Sollott, and D. B. Zorov. 2018. Mitochondrial membrane potential. Anal. Biochem. 552:50-59. https: //doi.org/10.1016/j.ab.2017.07.009. 